The Astrophysical Journal, 180:31-53, 1973 February 15

(C) 1973. The American Astronomical Society. All rights reserved. Printed in U.S.A.

\title{
MOLECULAR CLOUDS IN W49 AND W51
}

\author{
N. Z. SCOVILLE* \\ Department of Astronomy, Columbia University \\ AND \\ P. M. SOLOMON \\ School of Physics and Astronomy, University of Minnesota \\ Received 1972 June 30; revised 1972 September 28
}

\begin{abstract}
Radio observations of six molecular lines have been obtained in the W49 and W51 $\mathrm{H}$ in region sources as part of an investigation of the physical conditions in molecular clouds and the relationship of these clouds to the $\mathrm{H}$ II regions. The principal observations are maps with 4' spacing of the 6-cm formaldehyde $\left(\mathrm{H}_{2} \mathrm{CO}\right)$ absorption and strip maps with $1^{\prime}$ spacing of carbon monoxide $\left(\mathrm{CO}, J=1 \rightarrow 0\right.$ ) emission at $2.6 \mathrm{~mm}$. A few selected positions were also observed in ${ }^{13} \mathrm{CO}$ and $\mathrm{C}^{18} \mathrm{O}$ as well as the carbon monosulfide lines (CS, $3 \rightarrow 2$ and $\left.2 \rightarrow 1\right)$ at 2 and $3 \mathrm{~mm}$.

Seven distinct clouds are found, and five of these are associated with or near $\mathrm{H}$ II regions. The molecular clouds are all much larger than the $\mathrm{H}$ II regions; one near W51 (at $65 \mathrm{~km} \mathrm{~s}^{-1}$ ) extends over an area containing at least three $\mathrm{H}$ II regions and appears as a self-absorption feature in $\mathrm{CO}$. The mass of three of these molecular clouds is estimated to be at least $10^{4}-10^{5} M_{\odot}, 10$ times as great as the ionized regions. Average hydrogen molecule densities, over the entire clouds, are about $200-1000 \mathrm{~cm}^{-3}$; but near the $\mathrm{H}$ II regions there are probably compact, high-density $\left(\gg 10^{6} \mathrm{~cm}^{-3}\right)$ molecular regions which are responsible for the high-excitation lines of CS.

The excitation temperature of the 6- $\mathrm{cm} \mathrm{H}_{2} \mathrm{CO}$ transition in two clouds in the direction of W49A is estimated to be $1.76^{\circ} \pm 1.2^{\circ} \mathrm{K}$. The large velocity difference between these clouds and the $\mathrm{H}$ II region and the narrowness of the lines suggest that the clouds are dark nebulae and unrelated to W49A; however, there is $\mathrm{H}_{2} \mathrm{O}$ maser emission at the velocities of the dark cloud lines suggesting that some of the maser emission may be from foreground objects.
\end{abstract}

Subject headings: molecules, interstellar - nebulae - radio lines - star formation

\section{INTRODUCTION}

Initial surveys of 6-cm formaldehyde $\left(\mathrm{H}_{2} \mathrm{CO}\right)$ and 2.6-mm carbon monoxide (CO) lines have demonstrated their great potential for structural studies of dense, interstellar clouds. The ubiquity and short wavelengths of these lines permit high-angular-resolution observations of most clouds having more than a few magnitudes of visual extinction. Moreover, the $\mathrm{CO}$ line is always seen in emission, and the $\mathrm{H}_{2} \mathrm{CO}$ line, in absorption; they therefore provide complementary data vis-à-vis the spatial relationship of the continuum radiation sources and molecular clouds. In the vicinity of the galactic center, $\mathrm{H}_{2} \mathrm{CO}$ (Scoville, Solomon, and Thaddeus 1972) and $\mathrm{CO}$ (Solomon et al. $1972 b)$ observations reveal several molecular clouds with high densities $\left(\geqslant 10^{3} \mathrm{H} \mathrm{cm}^{-3}\right)$ and large masses $\left(10^{4}-10^{6} M_{\odot}\right)$. The most massive cloud in the galactic center is associated with a compact $\mathrm{H}$ II region (Sgr B2), and we inquire whether similar clouds exist near compact $\mathrm{H}$ II regions outside the galactic center. Away from the complexities of the galactic-center region, it should also be easier to study these clouds and investigate their relationship to the $\mathrm{H}$ II regions.

* Present address: School of Physics and Astronomy, University of Minnesota, Minneapolis, Minnesota. 
Here we report the results of $\mathrm{H}_{2} \mathrm{CO}, \mathrm{CO}$, and $\mathrm{CS}$ observations of the galactic radio sources W49 and W51. These regions were selected because broad molecular lines, similar to those seen in the galactic center, had previously been detected there (Zuckerman et al. 1970; Penzias, Jefferts, and Wilson 1971a) and the $\mathrm{H}$ II regions themselves have been the focus of many continuum and recombination-line studies. Both regions are completely obscured at visual wavelengths and were first detected in Westerhout's (1958) 22-cm survey. Investigations with high angular resolution have shown that the thermal emission from these sources comes mostly from compact $\mathrm{H}$ II regions and that nonthermal emission is also present.

The W49 source (fig. 1a) consists of a thermal component W49A (G43.2-0.0) and, $12^{\prime}$ to the east, a nonthermal component W49B (G43.3-0.2). Analysis of the W49A spectrum (Mezger, Schraml, and Terzian 1967) and high-resolution aperture-synthesis observations (Wynn-Williams 1969) show that the $\mathrm{H}$ II region consists of several small condensations of high electron density $\left(n_{e}>10^{4} \mathrm{~cm}^{-3}\right)$, embedded in a more extended and lower density $\left(n_{e} \sim 200 \mathrm{~cm}^{-3}\right)$ region. This model is further supported by the $109 \alpha$ and $137 \beta$ hydrogen recombination lines from W49A (Gordon and Wallace 1971). The distance of W49A, determined from its recombination-line velocity, is $14.1 \mathrm{kpc}$, and the mass of ionized gas is between $2 \times 10^{3} M_{\odot}$ and $10^{4} M_{\odot}$.

The W51 region is more complex than W49 (fig. 1b). The most intense component at $6 \mathrm{~cm}$ is $\mathrm{G} 49.5-0.4$, but there are at least six other thermal sources all superposed on a weak nonthermal background (Wilson et al. 1970; Shaver 1969). Interferometric observations at $11 \mathrm{~cm}$ show that G49.5-0.4 contains several very high brightness knots (Miley et al. 1970), perhaps similar to those found in W49A. The recombinationline velocities of all the W51 H II regions except G48.6+0.0 (not shown in fig. $1 b$ ) places them near the tangency point at $l=49^{\circ}$-that is, between 6.5 and $8 \mathrm{kpc}$ from the Sun. The mass of G49.5-0.4 is $3.7 \times 10^{3} M_{\odot}$, and the masses of the other $\mathrm{H}$ II regions shown in figure $1 b$ are between $2.8 \times 10^{2} M_{\odot}$ and $5.2 \times 10^{3} M_{\odot}$.

Observations of nonthermal OH emission in W49 and W51 show a close spatial and velocity coincidence between the $\mathrm{OH}$ clouds and several of the component $\mathrm{H}$ II regions (Rogers et al. 1966; Raimond and Eliasson 1969). Broad formaldehyde absorption lines have also been detected in the same directions (Zuckerman et al. 1970; Whiteoak and Gardner 1970); but to clarify the relationship between the molecular clouds and $\mathrm{H}$ II regions, it is clear that the molecular lines must be mapped at least over the full angular extent of the radio sources.

Our 6-cm $\mathrm{H}_{2} \mathrm{CO}$ observations were made on a grid with 4' spacing covering W49A and most of W51; 2.6-mm CO observations near the 6-cm peak of W49A were spaced by $1^{\prime}$ in the shape of a cross. The positions of these observations are shown superposed on the $6-\mathrm{cm}$ continuum brightness contours in figure 1 . Penzias et al. (1971a) have already mapped the CO lines near the peak (G49.5-0.4) in W51 to which we have added a few outlying points. Observations of ${ }^{13} \mathrm{CO}, \mathrm{C}^{18} \mathrm{O}$, and $\mathrm{CS}$ $(J=2 \rightarrow 1$ and $3 \rightarrow 2)$ were also made at a few positions suggested by the $\mathrm{CO}$ and $\mathrm{H}_{2} \mathrm{CO}$ observations (generally near the continuum peaks).

\section{OBSERVATIONS AND ANALYSIS}

\section{a) $\mathrm{H}_{2} \mathrm{CO}$}

The formaldehyde observations were made in 1971 April with the 140-foot (43-m) antenna and a cooled 6-cm parametric amplifier of the National Radio Astronomy Observatory (NRAO) ${ }^{1}$ in Green Bank, West Virginia. The measured half-power beamwidth (HPBW) and beam efficiency $(\eta)$ of the antenna are 6.6 and 0.8 at $6 \mathrm{~cm}$,

\footnotetext{
tion.

${ }^{1}$ Operated by Associated Universities, Inc., under contract with the National Science Founda-
} 


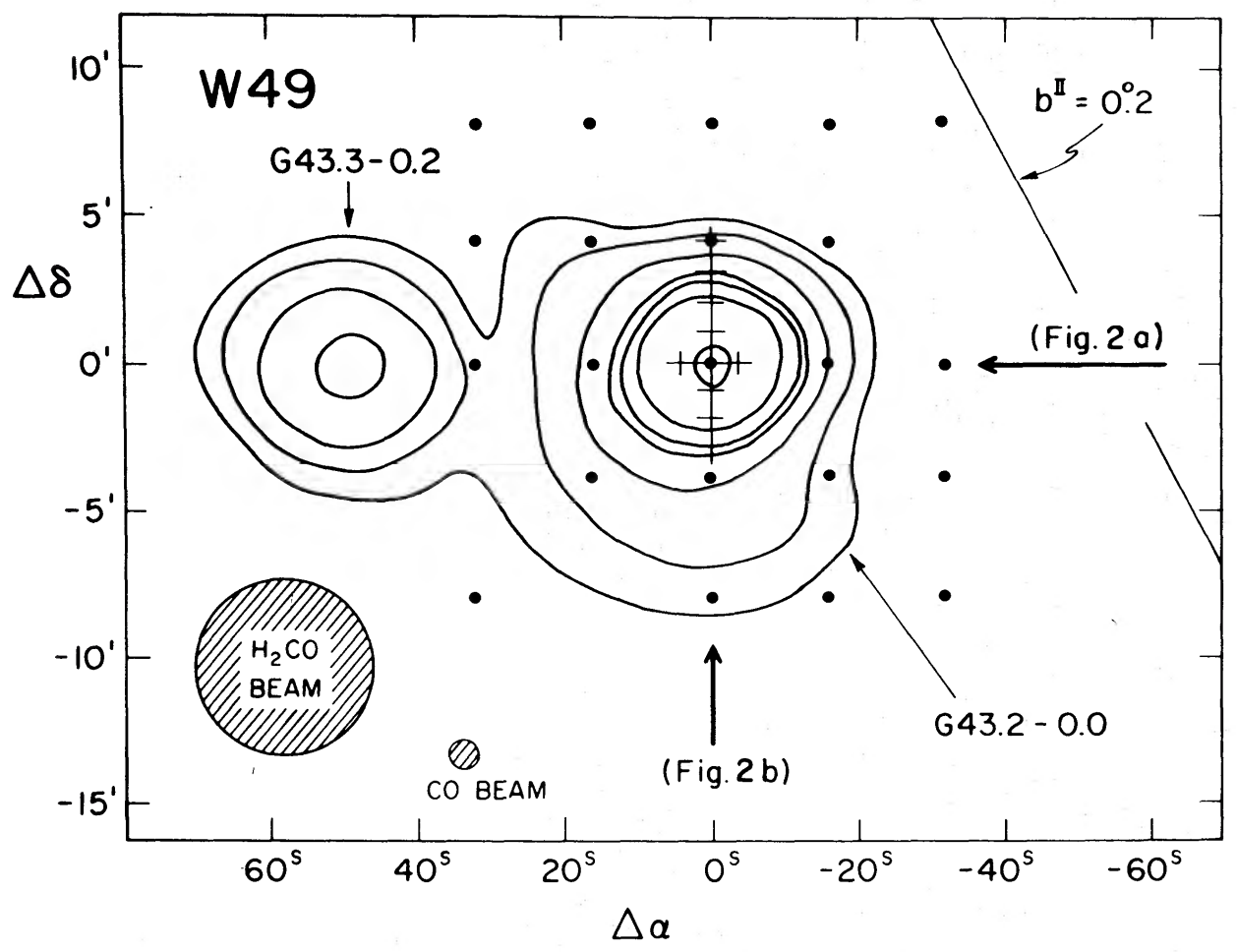

FIG. $1 a$

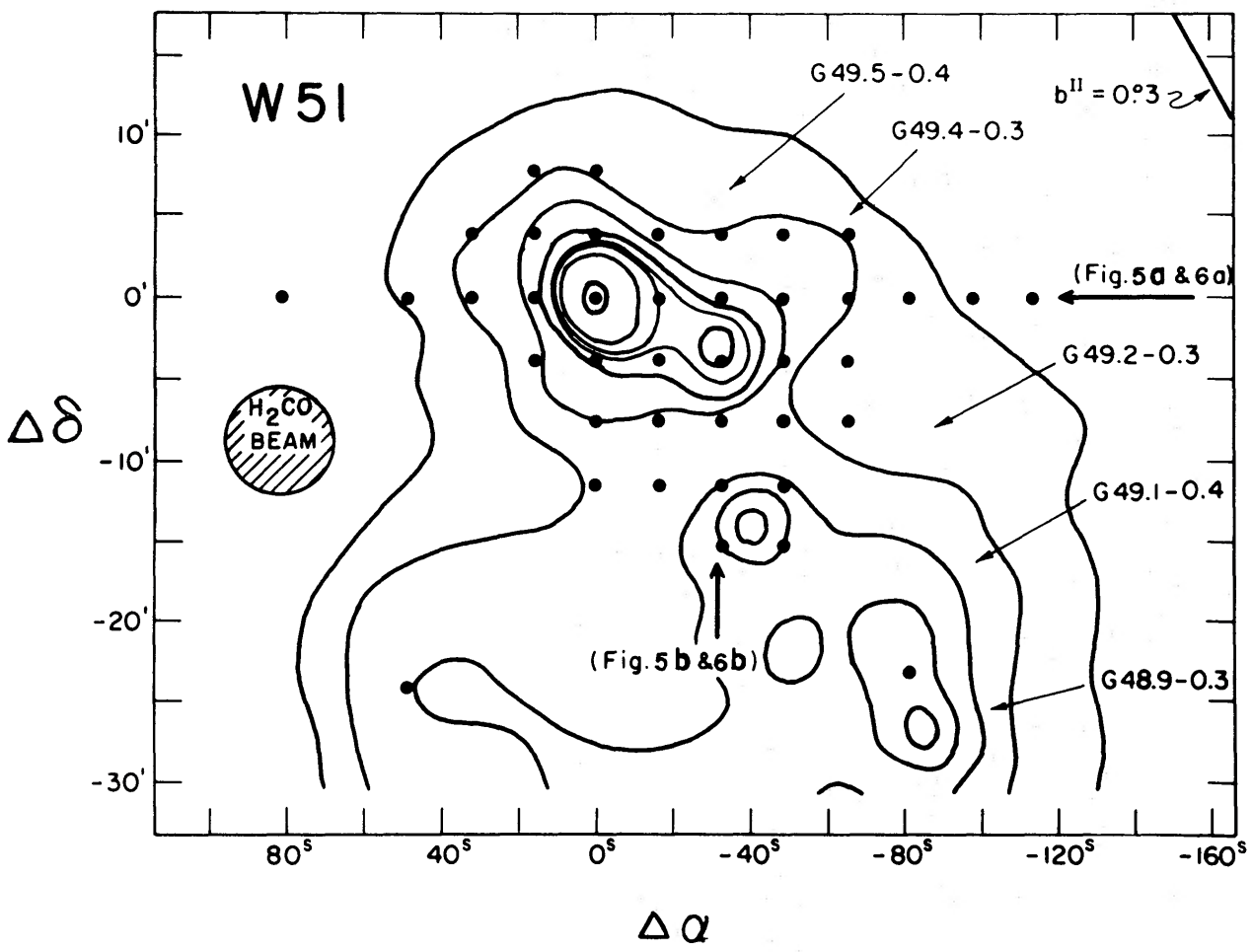

FIG. $1 b$

FIGS. $1 a$ and $1 b$.-Locations of $\mathrm{H}_{2} \mathrm{CO}$ and $\mathrm{CO}$ observations in W49 $(1 a)$ and W51 $(1 b)$ are indicated by dots and crosses superposed on isophotes of 6-cm continuum radiation (Goss and Shaver 1970; HPBW $=4^{\prime}$ ). The orientations of the spatial-velocity contour diagrams (figs. 2, 5, and 6) and the $\mathrm{H}_{2} \mathrm{CO}$ and $\mathrm{CO}$ beams are also shown. Isophote levels are at $1^{\circ}, 2^{\circ}, 4^{\circ}, 8^{\circ}, 12^{\circ}, 16^{\circ}$, and $60^{\circ} \mathrm{K}\left(T_{A}\right)$. 


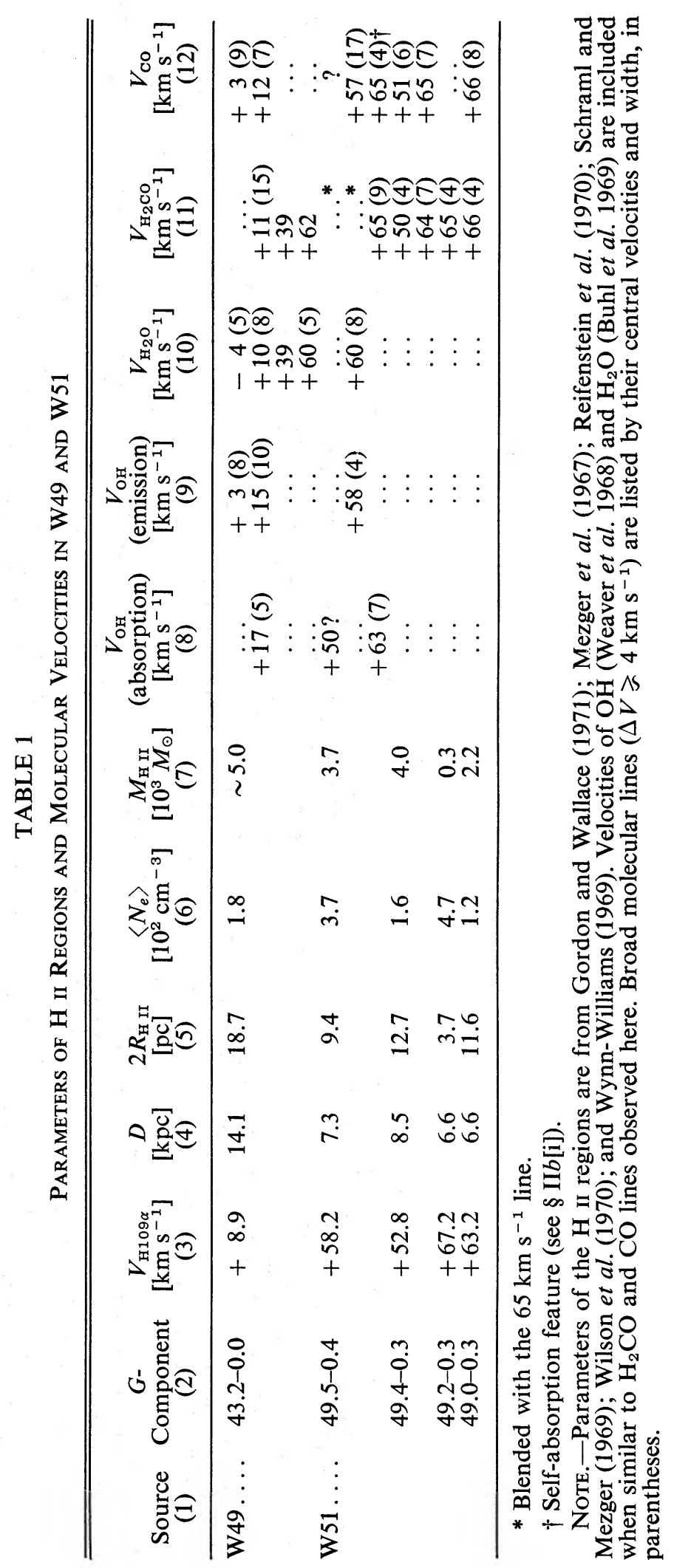


with the linear feed. The NRAO 384-channel autocorrelation receiver was used in the total power mode with a bandwidth of $2.5 \mathrm{MHz}\left(\sim 155 \mathrm{~km} \mathrm{~s}^{-1}\right.$ at $\left.6 \mathrm{~cm}\right)$, and the data were cosine filtered to a velocity resolution of $0.81 \mathrm{~km} \mathrm{~s}^{-1}$. (Higher spectral resolution is unwarranted in studies of cloud structure because of the $\mathrm{H}_{2} \mathrm{CO}$ hyperfinestructure width of $\sim 0.5 \mathrm{~km} \mathrm{~s}^{-1}$. In a few positions where low continuum intensities necessitated integrations up to an hour, the receiver was frequency switched at $1 \mathrm{~Hz}$ between the signal band and two adjacent reference bands. Radial velocities of the observed lines were computed using standard components for solar motion relative to the local standard of rest (LSR, Allen 1963), and $4829.65961 \mathrm{MHz}$ as the rest

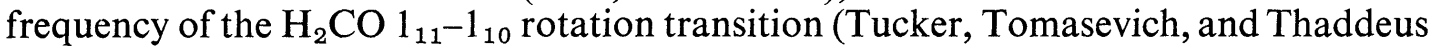
1970).

Observations of the 6- $\mathrm{cm} \mathrm{H}_{2} \mathrm{CO}$ line, to date, indicate that it is reasonable to adopt a constant excitation temperature. The $6-\mathrm{cm}$ transition has been seen only in absorption, in front of a wide variety of continuum sources as well as in dark nebulae behind which there is no discrete source of continuum radiation (Palmer et al. 1969). Thus the excitation temperature of the 6-cm levels, $T_{12}$, is very low in almost all molecular clouds. An estimate of the excitation temperature from the hyperfine intensity ratio in dark nebulae (Heiles 1972), where the absorption line is observed against the $2.7^{\circ} \mathrm{K}$ cosmic background radiation, gives $T_{12}=1.7^{\circ} \mathrm{K}$; and because there is no strong observational evidence that $T_{12}$ varies, we assume in calculating the $6-\mathrm{cm}$ optical depth $\tau$ that $T_{12}$ is constant and equal to $1.75^{\circ} \mathrm{K}$. (Small deviations, in the range $1^{\circ} \mathrm{K}<T_{12}<3^{\circ} \mathrm{K}$, will not substantially effect the derived parameters.) For a planeparallel cloud of formaldehyde molecules which uniformly covers all radiation sources contained in the antenna beam, the radiative-transfer relation is

$$
T_{L}^{\prime}=\left(T_{c}^{\prime}+T_{\mathrm{bg}}^{\prime}-T_{12}\right)\left(1-e^{-\tau}\right),
$$

where $T^{\prime}{ }_{L}, T^{\prime}{ }_{c}$, and $T_{\mathrm{bg}}$ are the brightness temperatures of the line, the discrete sources, and the cosmic background, and $\tau$ is the optical depth. (Absorption lines correspond to positive values of $T^{\prime}{ }_{L}$ and emission to negative values.)

Although the above is valid for the assumed conditions, in practice equation (1) serves only as a definition of apparent optical depth rather than true optical depth, which will be greater, since molecular clouds may be nonuniform or, as is frequently the case, be situated behind the most intense sources. However, where the same cloud is observed at several positions, with different continuum intensities $T^{\prime}{ }_{c}$, equation (1) may be used to determine how various geometrical arrangements of the continuum sources and a uniform cloud of absorbing molecules (for which the true optical depth is a constant) would appear observationally. We assume that both $T_{12}$ and $T^{\prime}$ bg are much less than $T^{\prime}{ }_{c}$, as is often the case for the 6- $\mathrm{cm} \mathrm{H}_{2} \mathrm{CO}$ lines. If this uniform cloud is in front of the continuum sources, the absorption line temperature $T^{\prime}{ }_{L}$ will vary in direct proportion to the continuum intensity at each position while the apparent optical depth $\tau$, determined by equation (1), will be constant across the cloud. On the other hand, if the cloud is behind the continuum sources, the absorption line temperature will remain constant, and the apparent optical depth will vary inversely with the continuum intensity. Assuming reasonable uniformity in the structure and excitation temperature, these considerations can be used to determine the relative positioning along the line of sight of the cloud and the sources.

The gas column densities corresponding to a given formaldehyde line may be calculated from its integrated optical depth. If $\tau \ll 1$ and the equivalent width $W$ $\left[\mathrm{km} \mathrm{s}^{-1}\right]$ is defined by

$$
W=\int_{\text {line }}\left[1-e^{-\tau(v)}\right] d v
$$


then the column density $N_{1}\left[\mathrm{~cm}^{-2}\right]$ of $\mathrm{H}_{2} \mathrm{CO}$ molecules in the lower 6-cm level is

$$
N_{1}=2.90 \times 10^{12} \mathrm{~W} /\left[1-\exp \left(-0.23 / T_{12}\right)\right] \text {. }
$$

The total formaldehyde column density is $3 N_{1} \rightarrow 7 N_{1}$ if the populations of the other rotational levels are described by Boltzmann distributions at $3^{\circ}-20^{\circ} \mathrm{K}$.

The column density of hydrogen (atomic and molecular), $N_{\Sigma \mathrm{H}}$, is apparently also proportional to the equivalent width of the $\mathrm{H}_{2} \mathrm{CO}$ line. Observations of local dark nebulae suggest that a cloud with about $5 \mathrm{mag}$ of visual extinction will have a $6-\mathrm{cm}$ equivalent width of $\sim 1 \mathrm{~km} \mathrm{~s}^{-1}$ (Kutner et al. 1973); then taking a gas-to-dust ratio of $\simeq 2 \times 10^{21} \mathrm{H} /$ magnitude, we obtain the approximate relation,

$$
N_{\Sigma \mathrm{H}}=W \times 10^{22} \mathrm{~cm}^{-2} \text {. }
$$

The validity of equation (4) rests on a constant formaldehyde-to-dust ratio in all dense clouds and a constant hydrogen-to-dust ratio in regions of both atomic and molecular hydrogen. Equation (4) is equivalent to $N_{1} / N_{\Sigma \mathrm{H}}=2.5 \times 10^{-9}$.

\section{b) $C O$ and $C S$}

The millimeter-wavelength lines of CO and CS in W49 and W51 were observed with a front-end receiver built at Bell Telephone Laboratories in Holmdel, New Jersey, and the NRAO 36-foot antenna at Kitt Peak, Arizona. The beam efficiency $(\eta)$ and width (HPBW) for the telescope are approximately 0.6 and $1^{\prime}$ at the CO and CS frequencies. Noise calibration was provided by a synchronous chopper wheel which alternately viewed the sky and a room-temperature absorbing sheet. These antenna temperatures $\left(T_{A}\right)$ can be converted to brightness temperatures $\left(T_{B}\right)$ by the following relation:

$$
\frac{1}{\left[\exp \left(h \nu / \kappa T_{B}\right)-1\right]}=\frac{\kappa T_{A}}{\eta h \nu}+\frac{1}{\left[\exp \left(h \nu / \kappa T_{\mathrm{bg}}\right)-1\right]} .
$$

For $h \nu / \kappa$ and $T_{\mathrm{bg}}<T_{B}$ (i.e., $T_{B}>10^{\circ} \mathrm{K}$ ), this simplifies to

$$
T_{B} \simeq T_{A} / \eta \text {. }
$$

Interpretation of the $\mathrm{CO}$ and $\mathrm{CS}$ lines is complicated by obvious variations in the excitation temperatures of these transitions from cloud to cloud and even within single clouds. All of the 2.6- $\mathrm{mm} \mathrm{CO}$ lines reported here are optically thick, and the different intensities must thus reflect the excitation temperature $T_{01}$ of the $J=0,1$ levels (assuming that the clouds are not patchy; see eq. [1]). The spontaneous transition rate $A_{10}$ is $6 \times 10^{-8} \mathrm{~s}^{-1}$, and the rotational excitation cross-section of $\mathrm{CO}$ for neutral collisions is $\sim 10^{-15} \mathrm{~cm}^{2}$. A neutral-hydrogen density $n$ greater than $10^{3} \mathrm{~cm}^{-3}$ will therefore be sufficient to couple the $2.6-\mathrm{mm}$ transition to the gas kinetic temperature, and the $\mathrm{CO}$ brightness temperature in dense clouds will give a reasonable estimate of the kinetic temperature. (The collisional excitation rate by electrons will exceed that by neutrals if the fractional electron abundance is $\geq 3 \times 10^{-3}$, which is definitely not expected in most dense molecular clouds [Solomon and Werner 1971].) Variations in $T_{01}$ will then be caused primarily by changes in either the gas density (if $n<10^{3} \mathrm{~cm}^{-3}$ ) or the gas kinetic temperature (if $n>10^{3} \mathrm{~cm}^{-3}$ ); an increase in $T_{01}$ (or the line intensity) may indicate not only a hotter region of gas but also perhaps a denser region. Similar arguments can be made for the CS transitions (Penzias et al. 1971b). The relatively large values of $A_{32}$ and $A_{21}\left(6.5 \times 10^{-5}\right.$ and $\left.2.1 \times 10^{-5} \mathrm{~s}^{-1}\right)$ suggest that these levels will not couple to the gas unless $n \geq 10^{6} \mathrm{~cm}^{-3}$. These lines have therefore been taken as indicators of high-density regions; however, alternative possibilities are suggested in $\S$ IV. 
In order to estimate the optical depth of the $\mathrm{CO}$ line and as part of a program on isotope ratios (see Penzias et al. 1972a) we observed the ${ }^{13} \mathrm{CO}$ and $\mathrm{C}^{18} \mathrm{O}$ lines in W51 and the ${ }^{13} \mathrm{CO}$ lines in W49. As can be seen from figure $9 a$, the intensity ratio $T^{13} \mathrm{co} / T_{\mathrm{C}^{18} \mathrm{O}}$ $=7 \pm 1.1 \mathrm{in} \mathrm{W} 51$, which is very close to the predicted ratio of 5.5, assuming terrestrial abundances $\left[{ }^{12} \mathrm{C} /{ }^{13} \mathrm{C}\right]=89$ and $\left[{ }^{16} \mathrm{O} /{ }^{18} \mathrm{O}\right]=499$. We regard this as substantial evidence in favor of terrestrial isotope ratios for both carbon and oxygen in W51 and assume that the same holds for W49.

The optical depth $\tau_{01}$ of the $\mathrm{CO}$ line can then be estimated from

$$
\tau_{01}=89 \ln \left(\frac{1}{1-T^{13} \mathrm{Co} / T_{\mathrm{CO}}}\right)
$$

The above assumes that the excitation temperature is the same for all isotopic species and may introduce some error since the thick $\mathrm{CO}$ lines originate from the closest optical depth at each velocity whereas the optically thin isotope lines have contributions through the cloud.

If all $\mathrm{CO}$ rotational levels are in thermal equilibrium at $T_{01}$, the column density of $\mathrm{CO}, N_{\mathrm{co}}$, is given by

$$
N_{\mathrm{CO}}=\frac{2.85 \times 10^{14} \tau_{01} \Delta V T_{01}}{\left[1-\exp \left(-5.5 / T_{01}\right)\right]} \mathrm{cm}^{-2},
$$

where $\Delta V$ is the line width in $\mathrm{km} \mathrm{s}^{-1}$. A lower limit to the total hydrogen column density is obtained by assuming that all the carbon is bound up in carbon monoxide. A C/H abundance ratio of $3 \times 10^{-4}$ (Allen 1963) then implies that

$$
\begin{gathered}
N_{\Sigma \mathrm{H}} \geq 3.3 \times 10^{3} N_{\mathrm{CO}} \mathrm{cm}^{-2} . \\
\text { III. RESULTS }
\end{gathered}
$$

The $\mathrm{H}_{2} \mathrm{CO}$ observations for W49 and W51 are presented in both velocity-spatial and two-dimensional spatial contour diagrams. The spatial coordinates used in these diagrams are centered on the strongest continuum radiation peak in each region (Reifenstein et al. 1970):

$$
\begin{aligned}
& \text { W49A(G43.2-0.0): } \quad \alpha_{1950}=19^{\mathrm{h}} 07^{\mathrm{m}} 54^{\mathrm{s}} ; \delta_{1950}=9^{\circ} 01^{\prime} 01^{\prime \prime} . \\
& \text { W51 }(\mathrm{G} 49.5-0.4): \quad \alpha_{1950}=19^{\mathrm{h}} 21^{\mathrm{m}} 23^{\mathrm{s}} ; \delta_{1950}=14^{\circ} 24^{\prime} 29^{\prime \prime} .
\end{aligned}
$$

In addition to the figures, line measurements (generally at positions of maximum apparent optical depth) are listed in table 2. The contents of the columns in table 2 are as follows: column (1), cloud name; columns (2) and (3), coordinate displacements at which greatest optical depth was observed; column (4), radial velocity at maximum optical depth; column (5), full line width at half-intensity; column (6), antenna temperature of 6-cm $\mathrm{H}_{2} \mathrm{CO}$ absorption line at this position; column (7), peak optical depth calculated using equation (1); column (8), equivalent width from equation (2); column (9), column density of formaldehyde molecules in the $1_{11}$ rotational level, $N_{1}$, as calculated from equation (3); column (10), estimated angular extent of the cloud; column (11), physical diameter calculated assuming the cloud is located near W49 $(14.1 \mathrm{kpc})$ or W51 $(6.5 \mathrm{kpc})$; column (12), maximum 2.6-mm CO antenna temperature in the cloud (these lines were not necessarily observed at the position of maximum $\mathrm{H}_{2} \mathrm{CO}$ optical depth given in cols. [2] and [3]); column (13), typical column density of hydrogen $N_{\Sigma \mathrm{H}}$, estimated in $\S$ III from the $\mathrm{H}_{2} \mathrm{CO}$ and $\mathrm{CO}$ lines (as discussed in $\S$ III, these estimates are probably minima); column (14), mass of molecular cloud. 


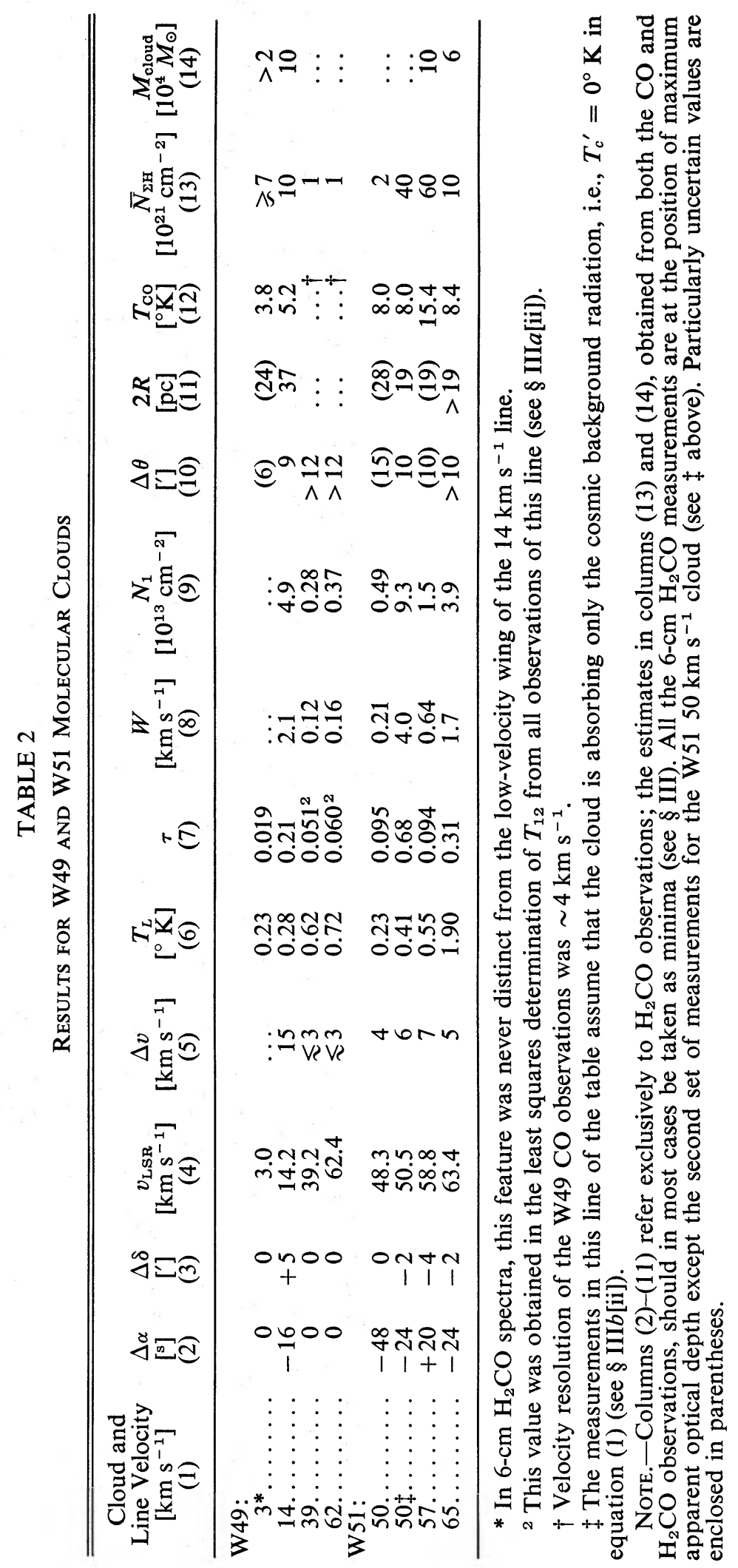


TABLE 3

CO Observational Results for W49A

\begin{tabular}{|c|c|c|c|}
\hline \multicolumn{2}{|c|}{ Position Relative to W49a } & \multirow{2}{*}{$\begin{array}{c}\text { LINE } 1 \\
\left(3 \pm 2 \mathrm{~km} \mathrm{~s}^{-1}\right) \\
\left.T_{\mathrm{Co}\left[{ }^{\circ} \mathrm{K}^{*}\right.}\right) \\
(3)\end{array}$} & \multirow{2}{*}{$\begin{array}{c}\text { LINE } 2 \\
\left(12 \pm 2 \mathrm{~km} \mathrm{~s}^{-1}\right): \\
\bar{T}_{\mathrm{Co}}\left[^{\circ} \mathrm{K}\right]^{*} \\
(4)\end{array}$} \\
\hline $\begin{array}{c}\Delta \alpha\left[^{\mathrm{s}}\right] \\
(1)\end{array}$ & $\begin{array}{c}\Delta \delta\left[^{\prime}\right] \\
(2)\end{array}$ & & \\
\hline 0 & +4 & $<0.2$ & 1.4 \\
\hline 0 & +3 & $<0.3$ & 3.0 \\
\hline 0 & +2 & $\leq 1.3 \dagger$ & 4.5 \\
\hline 0 & +1 & 2.5 & 3.8 \\
\hline 0 & 0 & 3.8 & 5.2 \\
\hline 0 & -1 & $<0.6$ & 2.3 \\
\hline 0 & -2 & $<0.3$ & 1.4 \\
\hline 0 & -3 & $<0.4$ & 1.1 \\
\hline 4 & 0 & 2.4 & 3.9 \\
\hline-4 & 0 & 2.5 & 3.7 \\
\hline
\end{tabular}

* Because the velocity resolution was only $4 \mathrm{~km} \mathrm{~s}^{-1}$, the line antenna temperatures listed in columns (3) and (4) are probably underestimated.

$\dagger$ The wing of line 2 extends smoothly out to $-5 \mathrm{~km} \mathrm{~s}^{-1}$.

Parameters of the $\mathrm{CO}$ emission lines near W49A, including the displacement coordinates, the peak antenna temperatures, and radial velocities of the two observed features, are listed in table 3. The CS observations are presented and discussed in $\S$ IV.

\section{a) $W 49$}

Figures $2 a$ and $b$ are contour diagrams of $\mathrm{H}_{2} \mathrm{CO}$ line temperature plotted in coordinate-velocity planes. They show observations along east-west and north-south strips which cross the W49A peak (see fig. 1a).

The 6-cm $\mathrm{H}_{2} \mathrm{CO}$ spectrum in W49A has lines at 14,39 , and $62 \mathrm{~km} \mathrm{~s}^{-1}$. The intensity variations are proportional to the continuum intensities at each position, indicating that they all originate in front of W49A. The $\mathrm{CO}$ spectrum shows an additional feature at $3 \mathrm{~km} \mathrm{~s}^{-1}$. The 3 and $14 \mathrm{~km} \mathrm{~s}^{-1}$ clouds may be near the $\mathrm{H}$ II regions since the $\mathrm{H} 109 \alpha$ recombination line is observed at $8.9 \mathrm{~km} \mathrm{~s}^{-1}$, while the two higher-velocity $\mathrm{H}_{2} \mathrm{CO}$ lines probably originate in clouds very distant from the $\mathrm{H}$ il region.

\section{i) Gas at 3 and $14 \mathrm{~km} \mathrm{~s}^{-1}$}

Both the 3 and $12 \mathrm{~km} \mathrm{~s}^{-1}$ CO lines in W49 (table 3 and fig. 3) are strongest at the continuum peak and maintain constant $\left( \pm 2 \mathrm{~km} \mathrm{~s}^{-1}\right)$ velocities across the source. (We group the $12 \mathrm{~km} \mathrm{~s}^{-1} \mathrm{CO}$ and the $14 \mathrm{~km} \mathrm{~s}^{-1} \mathrm{H}_{2} \mathrm{CO}$ lines together because their widths are much larger than the $2 \mathrm{~km} \mathrm{~s}^{-1}$ peak velocity difference.) The half-intensity contours for the two CO lines have diameters of 2.5 and $4^{\prime}$, respectively (as compared to the half-power width of 3'.1 for W49A [Mezger and Henderson 1967]), and the centers of these contours are $\sim 1^{\prime}$ north of W49A. This good agreement in size, position, and velocity of the two $\mathrm{CO}$ emission features with the $\mathrm{H}$ Ir region indicates a close physical relationship.

The intensity falloff, away from the $\mathrm{H}$ II region, of the $12 \mathrm{~km} \mathrm{~s}^{-1} \mathrm{CO}$ line could be due to a decrease of (1) the CO optical depth, (2) the density of exciting particles (neutrals and electrons), or (3) the gas kinetic temperature. As can be seen from the $\mathrm{H}_{2} \mathrm{CO}$ results in figure 4, the cloud is much larger than the $\mathrm{H}$ II region and not concentric. The maximum equivalent width is observed $6^{\prime}$ northwest of the $\mathrm{H}$ II region, and the full extent of the cloud has not been mapped. It may extend $12^{\prime}$ to the east of W49A since Whiteoak and Gardner (1970) observe a 6-cm line at $16.6 \mathrm{~km} \mathrm{~s}^{-1}$ in the 

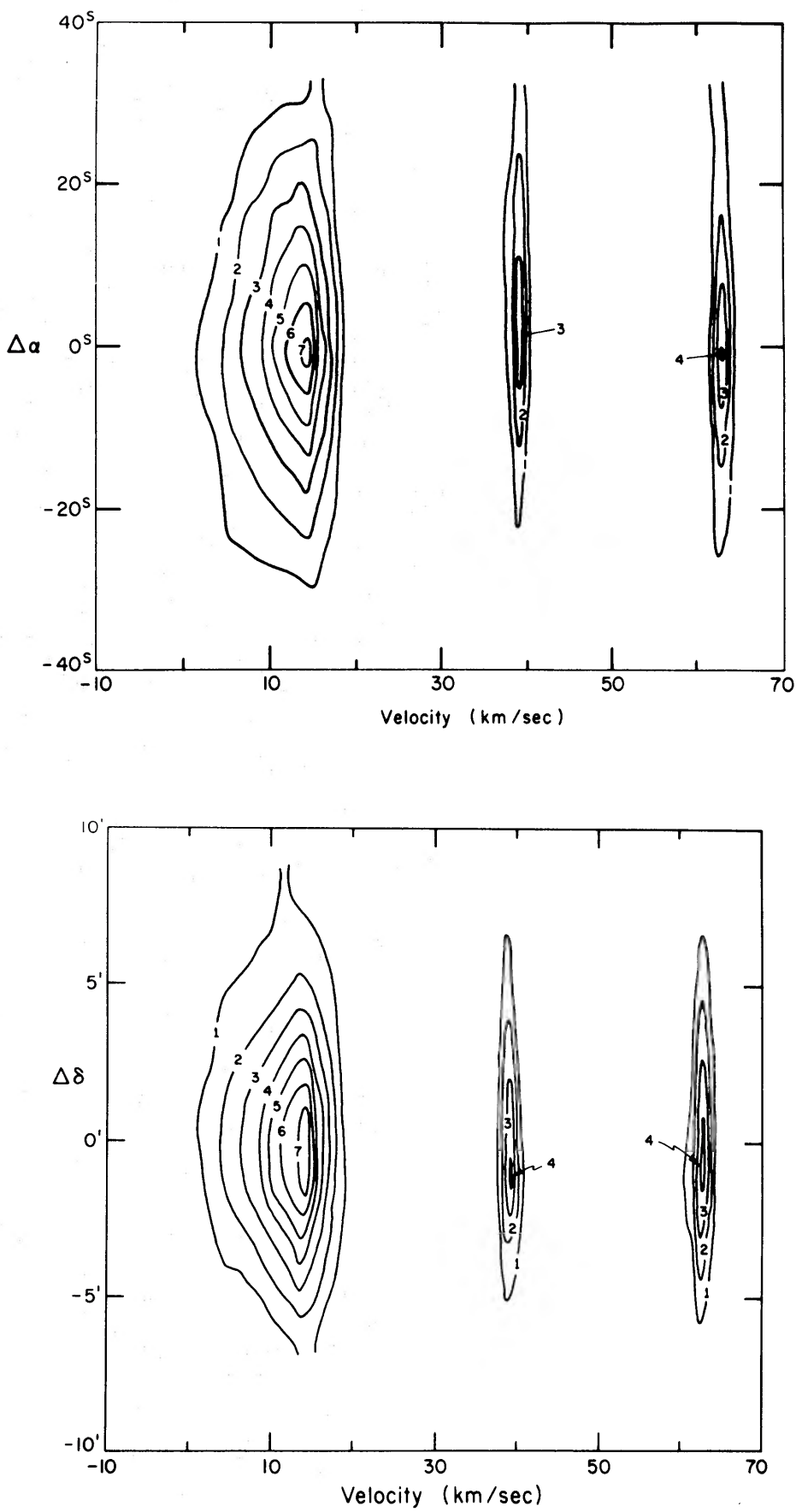

FIG. $2 a\left(\right.$ top ). - Contour diagram of $6-\mathrm{cm} \mathrm{H}_{2} \mathrm{CO}$ absorption $T_{L}(v)$, in the ( $\Delta \alpha$, velocity)-plane at $\Delta \delta=0^{\prime}$. Spatial orientation of diagram is shown in fig. $1 a ; \Delta \alpha$ and $\Delta \delta$ are right ascension and declination displacements from the W49A continuum peak. Contour unit is $0.15^{\circ} \mathrm{K}$ in antenna temperature.

FIG. $2 b$ (bottom).-Contour diagram of $6-\mathrm{cm} \mathrm{H}_{2} \mathrm{CO}$ absorption $T_{L}(v)$ in the $(\Delta \delta$, velocity)-plane at $\Delta \alpha=0^{\mathrm{s}} . \Delta \alpha, \Delta \delta$, and contour levels are defined as in fig. $2 a$. 
direction of W49B. The increasing $\mathrm{H}_{2} \mathrm{CO}$ column density to the northwest of W49A suggests strongly that the first and second (if the path length does not increase in the northwest of the cloud) of the above explanations are unlikely. In this cloud we therefore have evidence, albeit not conclusive, of highest kinetic temperatures close to the $\mathrm{H}$ II region. It is noteworthy that the $\mathrm{CO}$ line temperature $4^{\prime}$ north of W49A is similar to that observed in many dark nebulae by Penzias et al. (1972b); perhaps the high temperatures near the $\mathrm{H}$ II region are caused by heating of the cloud by the $\mathrm{H}$ II region. At any rate, we may safely conclude that the $\mathrm{CO}$ excitation temperature is highest near the $\mathrm{H}$ II region and that consequently the sizes of molecular regions are not reliably determined from intensity variations of a single molecular emission line (e.g., $\mathrm{CO})$.

Figure 4 indicates a size of $9 \times 9^{\prime}$ and average equivalent width of unity in the $\mathrm{H}_{2} \mathrm{CO}$ line at $14 \mathrm{~km} \mathrm{~s}^{-1}$. This yields a mass $\sim 10^{5} M_{\odot}$ (using eq. [4]), which is similar to that of molecular clouds in the galactic center and over 10 times that of the associated $\mathrm{H}$ II region (table 1). The $\mathrm{CO}$ observations yield estimates of the hydrogen column density which are consistent with those $\left(\sim 10^{22} \mathrm{~cm}^{-2}\right)$ obtained from the $\mathrm{H}_{2} \mathrm{CO}$ lines. If the ${ }^{12} \mathrm{C} /{ }^{13} \mathrm{C}$ abundance ratio is terrestrial and the other assumptions outlined in $\S$ II $b$ are valid, the optical depths of the ${ }^{13} \mathrm{CO}$ and $\mathrm{CO}$ lines shown in figures 3 are 0.7 and 60 . Using equations (7) and (8), we find $\mathrm{CO}$ and hydrogen column densities of $2 \times 10^{18}$ $\mathrm{cm}^{-2}$ and $\geqslant 7 \times 10^{21} \mathrm{~cm}^{-2}$ in both the 3 and $12 \mathrm{~km} \mathrm{~s}^{-1}$ clouds. The average gas densities in the molecular clouds are also within a factor 2 of the electron density $\left(\sim 200 \mathrm{~cm}^{-3}\right)$ in the extended component of the $\mathrm{H}$ II region.

The velocity characteristics of the $14 \mathrm{~km} \mathrm{~s}^{-1} \mathrm{H}_{2} \mathrm{CO}$ line are complicated, but there is a slight velocity gradient across the face of the cloud in a direction perpendicular to the galactic plane (fig. 4). In further support of the idea that this cloud is near W49A, we note that Gordon and Wallace (1971) observe a similar gradient for the $\mathrm{H} 109 \alpha$ recombination line of W49A. Two possible explanations of the gradient are rotation about an axis parallel to the galactic plane and expansion or contraction of the cloud along the direction of the gradient. Gordon and Wallace attribute the recombination-

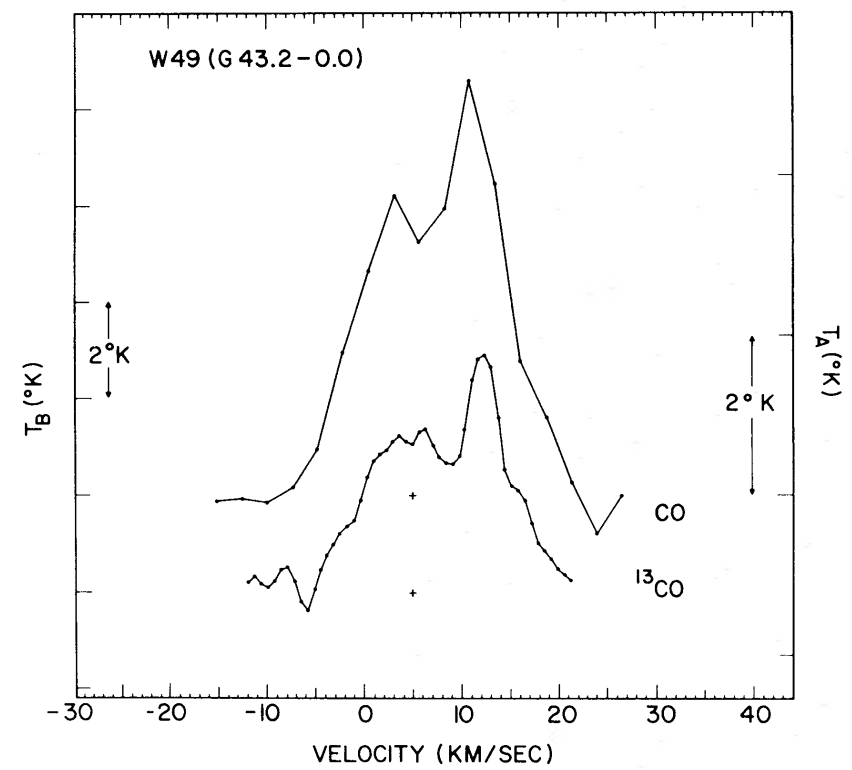

FIG. 3.-Spectra of $\mathrm{CO}$ and ${ }^{13} \mathrm{CO}$ emission at the W49A continuum peak $\left(\Delta \alpha=0^{\mathrm{s}}, \Delta \delta=0^{\prime}\right)$. The vertical scale on the right is antenna temperature $T_{A}$, and that on the left is $T_{A} / \eta(\approx$ brightness temperature $T_{B}$, for $T_{B}>10^{\circ} \mathrm{K}$ ). 


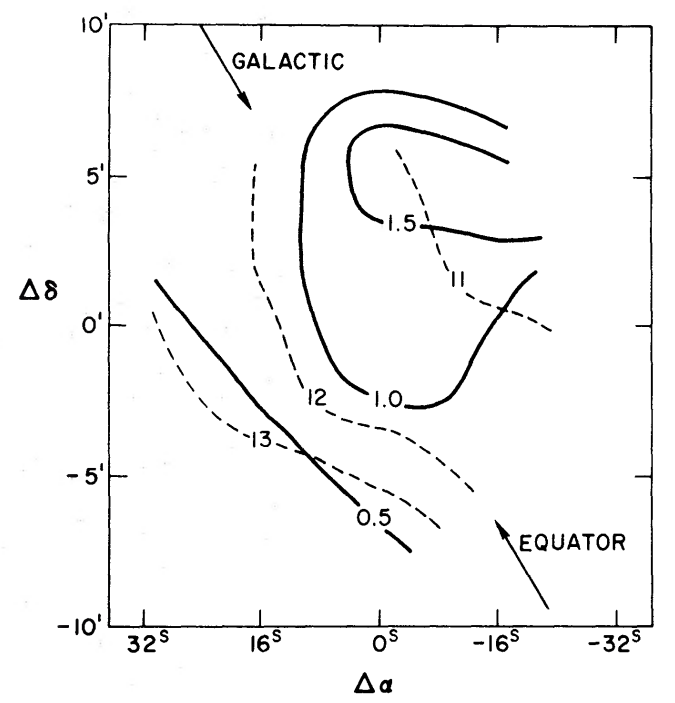

FIG. 4.-Contour diagram of equivalent width (solid contours) and mean velocity (dashed contours) in $(\Delta \alpha, \Delta \delta)$-plane for the $14 \mathrm{~km} \mathrm{~s}^{-1} \mathrm{H}_{2}$ CO line in W49A. Units of $W$ are $\mathrm{km} \mathrm{s}^{-1}$.

line gradient to expansion of hot gas at the ionization front against the surrounding anisotropic, cold $\mathrm{H}$ I gas. However, it seems unlikely that the gradient can be explained by a phenomenon as localized as the ionization front since the $\mathrm{H}_{2} \mathrm{CO}$ lines, which clearly refer to a much larger volume than the $\mathrm{H}$ il region, show the same effect.

As we have described above, the $\mathrm{CO}$ and $\mathrm{H}_{2} \mathrm{CO}$ observations furnish strong evidence for the $14 \mathrm{~km} \mathrm{~s}^{-1}$ molecular cloud being very near to W49A, although its radial velocity is about $5 \mathrm{~km} \mathrm{~s}^{-1}$ greater than the $\mathrm{H}$ II region. Moreover, the intensity variations of the $\mathrm{H}_{2} \mathrm{CO}$ line indicate that the cloud is situated in front of W49A; this molecular cloud is therefore moving towards the $\mathrm{H}$ II region at $5 \mathrm{~km} \mathrm{~s}^{-1}$. The absence of a distinct $\mathrm{H}_{2} \mathrm{CO}$ counterpart to the $3 \mathrm{~km} \mathrm{~s}^{-1} \mathrm{CO}$ cloud (at a limit of one-seventh the optical depth of the $14 \mathrm{~km} \mathrm{~s}^{-1} \mathrm{H}_{2} \mathrm{CO}$ line), together with the relatively slow variation of the absorption temperatures across W49A at $3 \mathrm{~km} \mathrm{~s}^{-1}$, suggests that this gas may be behind the $\mathrm{H}$ in region and thus is also approaching the $\mathrm{H}$ II region at about $6 \mathrm{~km} \mathrm{~s}^{-1}$. Indeed, the shape of the $14 \mathrm{~km} \mathrm{~s}^{-1} \mathrm{H}_{2} \mathrm{CO}$ line is similar to that expected from a spherical shell collapsing on the $\mathrm{H}$ II region at a velocity of $5 \mathrm{~km} \mathrm{~s}^{-1}$. But we must caution against such a simple picture, since the two $\mathrm{CO}$ lines show no indication of velocity shifts near the edge of the $\mathrm{H}$ II region. Moreover, the apparent optical depths at intermediate velocities of $5-10 \mathrm{~km} \mathrm{~s}^{-1}$ in the $\mathrm{H}_{2} \mathrm{CO}$ line are constant across W49A within the noise limit of these observations. Thus the fading of the extended low-velocity wing of the $14 \mathrm{~km} \mathrm{~s}^{-1}$ line as one moves off the $\mathrm{H}$ II region (fig. 2) appears to be not a real change in the velocity distribution of the molecules but merely the effect of decreasing illumination in the profile by the lower continuum intensities. (This point definitely requires further investigation with a smaller telescope beam and higher sensitivity.)

\section{ii) Gas at 39 and $62 \mathrm{~km} \mathrm{~s}^{-1}$}

The narrow $\mathrm{H}_{2} \mathrm{CO}$ lines at 39 and $62 \mathrm{~km} \mathrm{~s}^{-1}$ may originate from dark clouds that happen to be along the line of sight to W49A. Carbon monoxide emission was not detected at these velocities, but this was probably because of the low velocity resolution $\left(\sim 4 \mathrm{~km} \mathrm{~s}^{-1}\right)$ of the $\mathrm{CO}$ observations. We have used the $\mathrm{H}_{2} \mathrm{CO}$ lines to estimate the excitation temperature of the $6-\mathrm{cm}$ levels from the observed variations in line temperature as a function of the continuum intensity. A least-squares solution was found 
using equation (1) and assuming that the peak optical depth and $T_{12}$ were constant in each of the clouds at all positions for which the lines were visible above the noise. The combination of the separate $T_{12}$ calculated for each cloud yields $T_{12}=1.76^{\circ} \mathrm{K} \pm$ $1.2^{\circ} \mathrm{K}$, consistent with the value obtained for dark clouds in the solar neighborhood $(\S \mathrm{II} a)$. These two lines would be difficult to observe in absorption against only the microwave background, because their optical depths $(\sim 0.055)$ would produce a line of less than $0.05^{\circ} \mathrm{K}$ if the excitation temperature has the above value. The small equivalent widths of the lines are suggestive of low gas densities in the two clouds.

Of great potential interest is the fact that $\mathrm{H}_{2} \mathrm{O}$ emission lines are also observed at 39 and $60 \mathrm{~km} \mathrm{~s}^{-1}$ in W49A (see fig. 2 of Buhl et al. 1969). Although it cannot be ruled out, a coincidental velocity correspondence between $\mathrm{H}_{2} \mathrm{O}$ and $\mathrm{H}_{2} \mathrm{CO}$ features seems unlikely in view of the number of lines in each spectrum. This raises the interesting possibility that some of the $\mathrm{H}_{2} \mathrm{O}$ sources are located in foreground dark clouds which are not intimately connected with the $\mathrm{H}$ il regions. Additional searches for narrow $\mathrm{H}_{2} \mathrm{CO}$ lines at the velocities of $\mathrm{H}_{2} \mathrm{O}$ lines must be carried out in order to check this possibility.

\section{b) W51}

Figures 5 and 6 are contour diagrams of line temperature and optical depth, respectively, for $\mathrm{H}_{2} \mathrm{CO}$ absorption in W51. The spatial orientation of the two sets of data is shown in figure $1 b$.

In discussing the molecular lines of the W51 region, we consider three separate clouds with velocities of 50,57 , and $65 \mathrm{~km} \mathrm{~s}^{-1}$. Our observations indicate that all three clouds are in the vicinity of the W51 thermal sources and thus may be physically related; but because their lines and spatial characteristics are very different, we will discuss them separately.

\section{i) Gas at $65 \mathrm{~km} \mathrm{~s}^{-1}$}

The most intense $6-\mathrm{cm}$ absorption line in W51 has a velocity of $\sim 65 \mathrm{~km} \mathrm{~s}^{-1}$. Its maximum antenna temperature of $4.5^{\circ} \mathrm{K}$ in the direction of $\mathrm{G} 49.5-0.4$ implies that the $65 \mathrm{~km} \mathrm{~s}^{-1}$ cloud lies in front of this $\mathrm{H} \mathrm{II}$ region, and increases in the line temperature near the sources G49.4-0.3 and G49.2-0.3 suggest that it is also in front of them (see fig. $5 b$ ). Contours of equivalent width and mean velocity for this line are presented in figure $7 .{ }^{2}$ The line has a maximum equivalent width of $2.01 \mathrm{~km} \mathrm{~s}^{-1} 4^{\prime}$ north of G49.5-0.4 while the angular diameter of G49.5-0.4 is only 4'3. (Mezger and Henderson 1967), indicating that the molecular column density definitely does not peak near the center of this intense source. In fact, comparison of the continuum and equivalent width maps (figs. $1 b$ and 7 ) shows that the molecular cloud extends over much of the W51 region with its shape elongated along the direction in which the thermal sources lie (i.e., parallel to the galactic plane)!

Wilson et al. (1970) and Reifenstein et al. (1970) have detected $\mathrm{H} 109 \alpha$ recombination lines from seven of the thermal sources in W51, five of which are shown in figure $1 b$. The two northernmost sources, G49.5-0.4 and G49.4-0.3, have velocities of 58.2 and $52.8 \mathrm{~km} \mathrm{~s}^{-1}$ whereas the more southerly sources shown in figure $1 b$ have an average velocity of $67.7 \mathrm{~km} \mathrm{~s}^{-1}$. On the basis of this velocity difference between the southern and northern sources, Wilson et al. conclude that there are two distinct and unrelated associations of giant $\mathrm{H}$ II regions $\left(\sim 3 \times 10^{3} M_{\odot}\right)$ at distances of 6.5 and $8.0 \mathrm{kpc}$. However, as can be seen from figure 7, the distribution of the $65 \mathrm{~km} \mathrm{~s}^{-1}$

\footnotetext{
${ }^{2}$ In calculating $W$, the integration was between 55 and $70 \mathrm{~km} \mathrm{~s}^{-1}$; a small contribution from the $57 \mathrm{~km} \mathrm{~s}^{-1}$ cloud is therefore included. The absence of contours in the lower left portion of the figure should not be taken as indicating that the line is undetectable, since no observations were made there.
} 

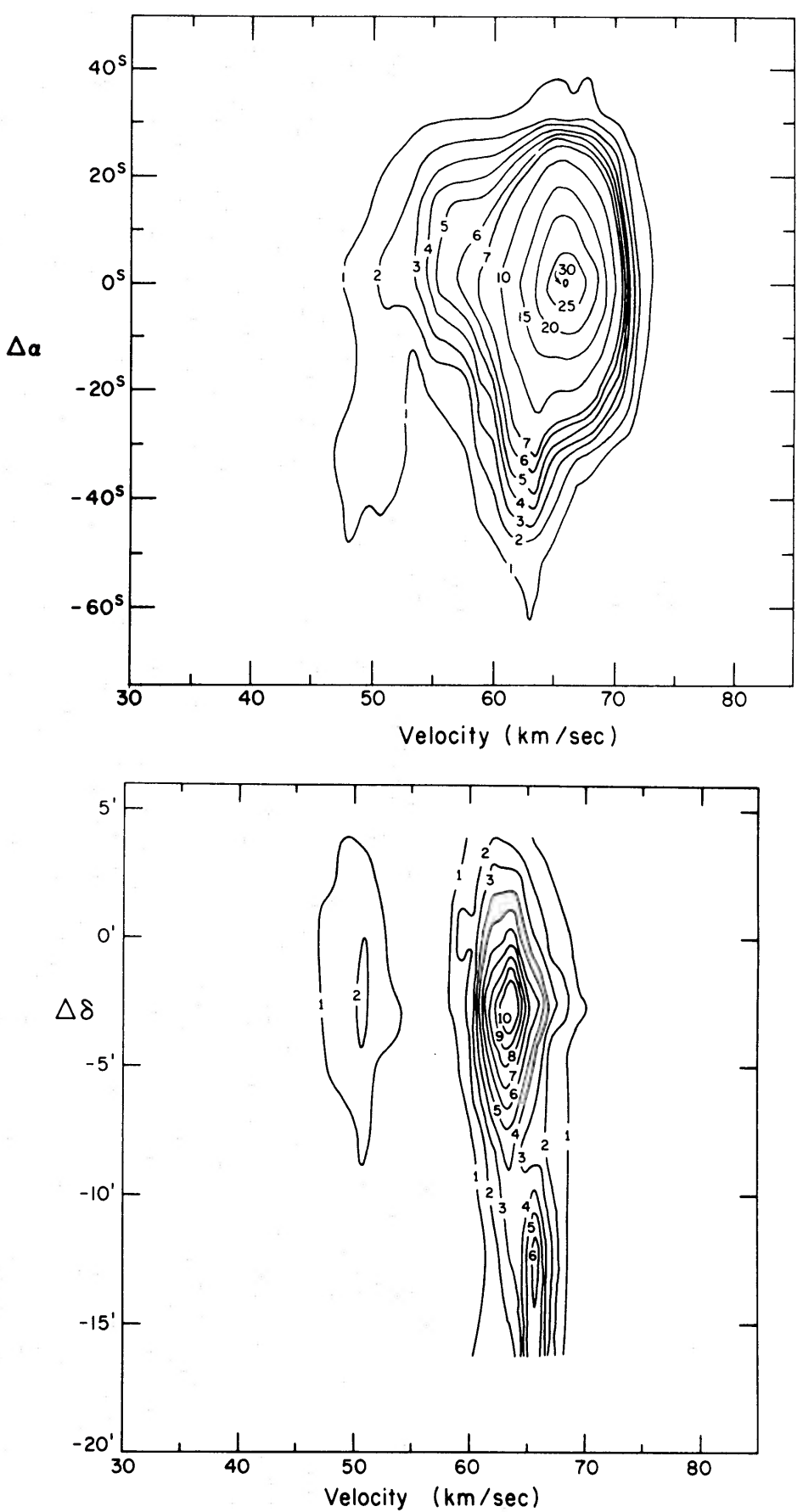

FIG. $5 a$ (top).-Contour diagram of 6-cm $\mathrm{H}_{2} \mathrm{CO}$ absorption $T_{L}(v)$, in the ( $\Delta \alpha$, velocity)-plane at $\Delta \delta=0^{\prime}$. Spatial orientation of diagram is shown in fig. $1 b ; \Delta \alpha$ and $\Delta \delta$ are right ascension and declination displacements from W51 (G49.5-0.4). Contour unit is $0.15^{\circ} \mathrm{K}$ in antenna temperature.

FIG. $5 b\left(\right.$ bottom).-Contour diagram of $6-\mathrm{cm} \mathrm{H}_{2} \mathrm{CO}$ absorption $T_{L}(v)$ in the $(\Delta \delta$, velocity)-plane at $\Delta \alpha=-32^{\mathrm{s}} . \Delta \alpha, \Delta \delta$, and contour levels are defined as in fig. $5 a$. 

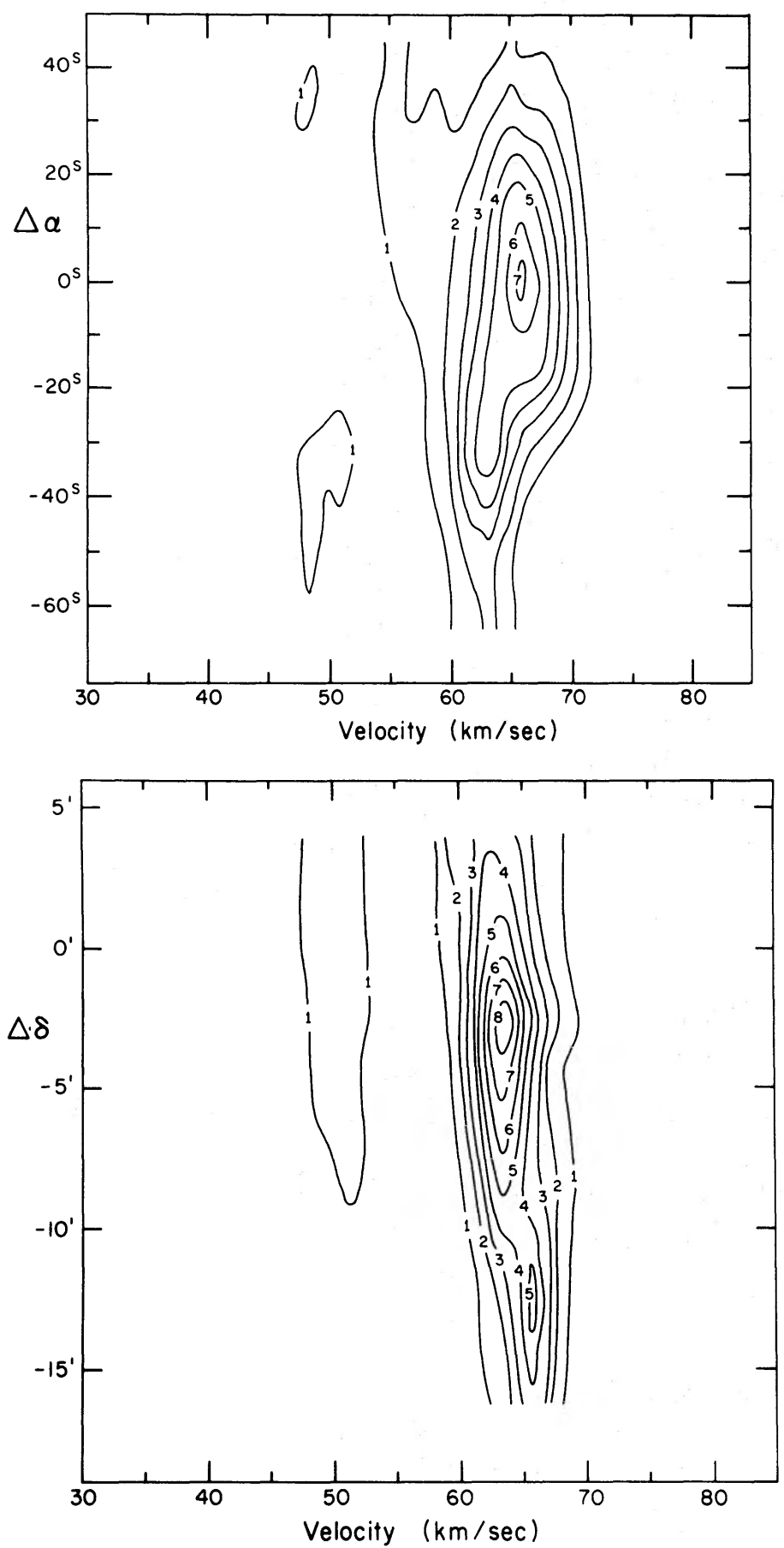

FIG. $6 a(t o p)$.-Contour diagram of $\mathrm{H}_{2} \mathrm{CO}$ optical depth $\tau(v)$, in the ( $\Delta \alpha$, velocity)-plane at $\Delta \delta=0^{\prime}$. Optical-depth unit is 0.03 . (Optical depths in fig. 6 were calculated from data of fig. 5 , the measured continuum temperatures, and eq. [1].)

FIG. $6 b$ (bottom).-Contour diagram of $\mathrm{H}_{2} \mathrm{CO}$ optical depth $\tau(v)$ in the $(\Delta \delta$, velocity)-plane at $\Delta \alpha=-32^{\mathrm{s}}$. Optical-depth unit is 0.03 . 




Fig. 7.-Contour diagram of equivalent width (solid contours) and mean velocity (dashed contours $)$ in $(\Delta \alpha, \Delta \delta)$-plane for the $65 \mathrm{~km} \mathrm{~s}^{-1} \mathrm{H}_{2} \mathrm{CO}$ line in W51. $\Delta \alpha$ and $\Delta \delta$ are defined as in fig. $5 a$, and units of $W$ are $\mathrm{km} \mathrm{s}^{-1}$.

molecules more closely resembles that of all the thermal sources rather than just the southerly ones. The cloud is probably not associated with one single $\mathrm{H}$ in region but instead is part of one large complex that includes both molecular clouds and $\mathrm{H}$ II regions. This would in turn imply that all the $\mathrm{H}$ II regions are at nearly the same distance. There is a definite shifting of the $65 \mathrm{~km} \mathrm{~s}^{-1}$ line peak to higher velocities in the vicinity of the higher-velocity southern sources (fig. $6 b$ ) and a weak suggestion that the mean velocity of the gas (fig. 7) is $\sim 1 \mathrm{~km} \mathrm{~s}^{-1}$ higher in the direction of the two sources G49.5-0.4 and G49.2-0.3. We also note that the highest optical depths in figures $6 a$ and $6 b$ occur at the right ascension of G49.5-0.4 and the declinations of G49.4-0.3 and G49.2-0.3. Although possibly real, these local increases in peak optical depth near the $\mathrm{H}$ il regions could also arise from underestimation of the continuum intensity near the continuum peaks or too low a value for $T_{12}$ in equation (1). High-resolution, low-noise observations are certainly required before the effect can be considered real.

From the 6-cm data in figure 7 and assuming that the cloud is near the $\mathrm{H}$ II regions, we find that its mass is $6 \times 10^{4} M_{\odot}$-almost 10 times the mass of the three W51 $\mathrm{H}$ II regions contained in this same portion of sky (table 1). The average hydrogen column density $\left(\sim 10^{22} \mathrm{~cm}^{-2}\right)$ corresponds to a gas density of $\sim 200 \mathrm{~cm}^{-3}$. 
The CO spectrum of $\mathrm{G} 49.5-0.4$ (fig. $9 a$ ) shows a strong, broad line at $57 \mathrm{~km} \mathrm{~s}^{-1}$ and a secondary peak at $69 \mathrm{~km} \mathrm{~s}^{-1}$. At $65 \mathrm{~km} \mathrm{~s}^{-1}$ where the peak $\mathrm{H}_{2} \mathrm{CO}$ absorption occurs, there is only a local minimum in the $\mathrm{CO}$ emission. In contrast, the $\mathrm{CO}$ spectrum of G49.0-0.3 (fig. $9 b$ ) shows a single peak at $66 \mathrm{~km} \mathrm{~s}^{-1}$. The $69 \mathrm{~km} \mathrm{~s}^{-1}$ emission, which at first would appear to be a counterpart of the $65 \mathrm{~km} \mathrm{~s}^{-1} \mathrm{H}_{2} \mathrm{CO}$ absorption, is observed only where the $57 \mathrm{~km} \mathrm{~s}^{-1}$ line is intense and thus is probably not from a separate cloud. We suggest that this emission is merely the wing of the $57 \mathrm{~km} \mathrm{~s}^{-1}$ line and that the local minimum is due to absorption by cold $\mathrm{CO}$ in the large $65 \mathrm{~km} \mathrm{~s}^{-1}$ cloud lying in front of the $57 \mathrm{~km} \mathrm{~s}^{-1}$ emission region. This interpretation is supported by the ${ }^{13} \mathrm{CO}$ and $\mathrm{C}^{18} \mathrm{O}$ spectra of figure $9 a$ which show no peak at $69 \mathrm{~km} \mathrm{~s}^{-1}$ but instead a shoulder at about $65 \mathrm{~km} \mathrm{~s}^{-1}$. The $\mathrm{CO}$ self-absorption implies an excitation temperature $T_{01}$, probably also a kinetic temperature ( $\S \mathrm{II} b$ ), of only $\sim 9^{\circ} \mathrm{K}$ (using eq. [5a]) in the $65 \mathrm{~km} \mathrm{~s}^{-1}$ cloud near G49.5-0.4. In the direction of G49.9-0.3 (fig. $9 b), T_{01}$ is much higher $\left(\sim 16^{\circ} \mathrm{K}\right)$ and the $\mathrm{CO} /{ }^{13} \mathrm{CO}$ intensity ratio of 5 gives $\tau_{01}=20$. The CO column density is then $\sim 10^{18} \mathrm{~cm}^{-2}$. Near G49.5-0.4 the observed $\mathrm{CO} /{ }^{13} \mathrm{CO}$ intensity ratio of 1.5 at $65 \mathrm{~km} \mathrm{~s}^{-1}$ could imply that $\tau_{01} \sim 100$; however, this is certainly an overestimate, since, based on our interpretation above, the $65 \mathrm{~km} \mathrm{~s}^{-1}$ ${ }^{13} \mathrm{CO}$ emission, if optically thin, will contain a contribution from gas in the hot $57 \mathrm{~km} \mathrm{~s}^{-1}$ cloud whereas the optically thick $\mathrm{CO}$ emission will come solely from the cold $\mathrm{H}_{2} \mathrm{CO}$ cloud. A reliable $\mathrm{CO}$ column density estimate for the $65 \mathrm{~km} \mathrm{~s}^{-1}$ cloud near G49.5-0.4 is therefore presently impossible.

\section{ii) Gas at $50 \mathrm{~km} \mathrm{~s}^{-1}$}

The 6-cm line at $50 \mathrm{~km} \mathrm{~s}^{-1}$ becomes plainly visible and separate from the lowvelocity wing of the $65 \mathrm{~km} \mathrm{~s}^{-1}$ line at positions about $30^{\mathrm{s}}$ to the west of G49.5-0.4 (fig. 5a). The absorption line temperature at this velocity increases only slightly, if at all, in the direction of G49.5-0.4, so that the apparent optical depth (fig. $6 a$ ) reaches a minimum there. This behavior of the line temperature and apparent optical depth is just that expected if the cloud is situated behind G49.5-0.4 ( $\S$ II $a$ ).

Figure 8 shows equivalent width contours of the $50 \mathrm{~km} \mathrm{~s}^{-1}$ line over the region in which it is stronger than the low-velocity wing of the $65 \mathrm{~km} \mathrm{~s}^{-1}$ feature. Because the $50 \mathrm{~km} \mathrm{~s}^{-1}$ line probably originates from behind $\mathrm{G} 49.5-0.4$, the equivalent widths were calculated on the assumption that the cloud is absorbing only the cosmic background radiation (i.e., $T^{\prime}{ }_{C}=0^{\circ} \mathrm{K}$ in eq. [1]). The presence of a diffuse galactic background, not included because of its uncertain intensity, would decrease the values of the contour levels but would not affect their shape. It is entirely possible that the source G49.4-0.3 is being absorbed by the $50 \mathrm{~km} \mathrm{~s}^{-1}$ cloud, but the difficulty of separating the radiation contribution of this source from G49.5-0.4 forced us to assume that both sources are in front of the cloud for calculation of the equivalent widths.

The position of maximum equivalent width ${ }^{3}$ for the $50 \mathrm{~km} \mathrm{~s}^{-1}$ cloud lies only $3^{\prime}$ away from the $\mathrm{H}$ II region $\mathrm{G} 49.4-0.3$ whose recombination-line velocity is $52.8 \mathrm{~km} \mathrm{~s}^{-1}$ (Wilson et al. 1970); the cloud and this $\mathrm{H}$ II region are therefore probably close to each other. A good part of the $3^{\prime}$ discrepancy in positions can perhaps be accounted for by interference from the wings of the 65 and $57 \mathrm{~km} \mathrm{~s}^{-1}$ lines which are very strong in the direction on G49.5-0.4. Both the peak velocity and the mean velocity of the $50 \mathrm{~km} \mathrm{~s}^{-1}$ line are virtually constant over the region in which the line was detected.

The CO spectrum in the direction of G49.5-0.4 (fig. $9 a$ ) shows weak $\left(T_{A} \simeq 4^{\circ} \mathrm{K}\right.$ ) emission at $50 \mathrm{~km} \mathrm{~s}^{-1}$. To the west of G49.5-0.4 (data not shown) the $57 \mathrm{~km} \mathrm{~s}^{-1}$ line weakens and the $50 \mathrm{~km} \mathrm{~s}^{-1}$ line becomes a distinct feature with a line antenna

\footnotetext{
${ }^{3}$ Also the position of maximum integrated line temperature since the $W$ contours were calculated under the assumption of a constant background radiation.
} 


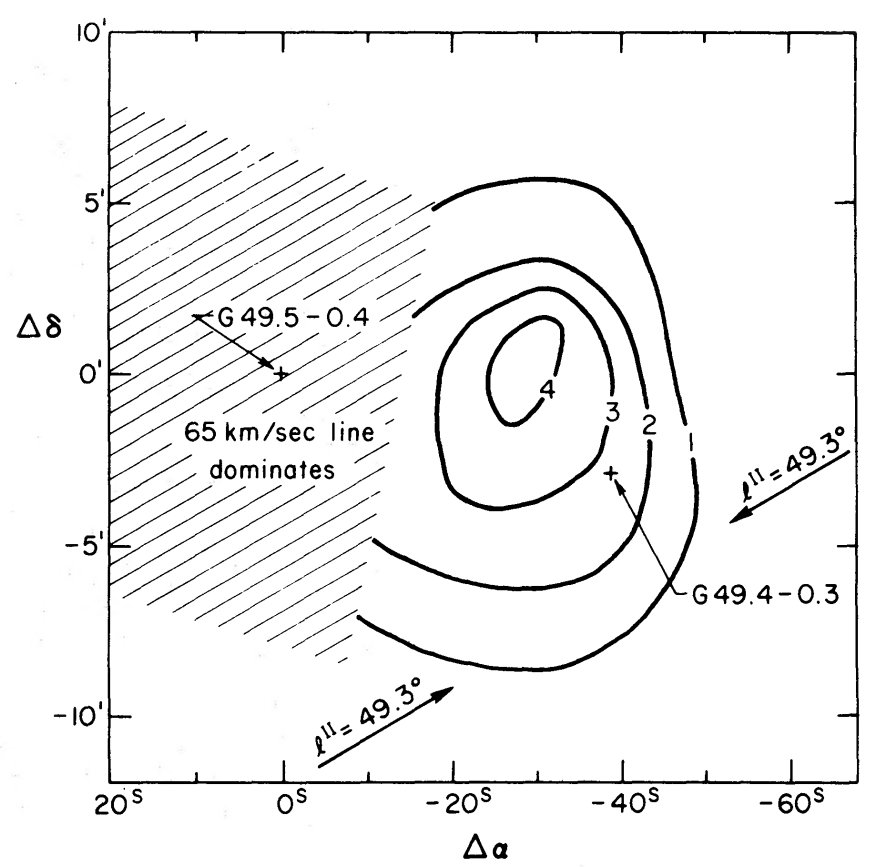

FIG. 8.-Contour diagram of equivalent width in the $(\Delta \alpha, \Delta \delta)$-plane for the $50 \mathrm{~km} \mathrm{~s}^{-1} \mathrm{H}_{2} \mathrm{CO}$ line in W51. $\Delta \alpha$ and $\Delta \delta$ are defined as in fig. $5 a$, and units of $W$ are $\mathrm{km} \mathrm{s}^{-1}$. In the shaded region the wing of the $65 \mathrm{~km} \mathrm{~s}^{-1}$ line extends to low velocities and makes measurements of the $50 \mathrm{~km} \mathrm{~s}^{-1}$ line impossible. ( $W$ is calculated under the assumption that the cloud is located behind the continuum source; see $\S$ III $b$ [ii].)

temperature of $8^{\circ} \mathrm{K}$ in the direction of $\mathrm{G} 49.4-0.3$. Because ${ }^{13} \mathrm{CO}$ observations do not extend to $\mathrm{G} 49.4-0.3$ and the $\mathrm{H}_{2} \mathrm{CO}$ optical depths are uncertain, we forgo a quantitative comparison of the $\mathrm{CO}$ and $\mathrm{H}_{2} \mathrm{CO}$ lines in this cloud.

\section{iii) Gas at $57 \mathrm{~km} \mathrm{~s}^{-1}$}

The $57 \mathrm{~km} \mathrm{~s}^{-1}$ gas (fig. $9 a$ ) shows up as the most intense feature in the mm emission spectra of CO, CN, HCN, $\mathrm{H}_{2} \mathrm{CO}$, and CS (Penzias et al. 1971a, $b$; Jefferts, Penzias, and Wilson 1970; Snyder and Buhl 1971; Thaddeus et al. 1971), but is only faintly visible in $6-\mathrm{cm} \mathrm{H}_{2} \mathrm{CO}$ absorption. All of the $57 \mathrm{~km} \mathrm{~s}^{-1}$ millimeter lines have their peak emission occurring less than $1^{\prime}$ from the center of G49.5-0.4; and the halfintensity size of the $\mathrm{CS}$ and millimeter $\mathrm{H}_{2} \mathrm{CO}$ emission region is $3^{\prime}$, approximately the size of the $\mathrm{H}$ II region. The case for close proximity of this gas to the $\mathrm{H}$ II region is made even more conclusive by the $58.2 \mathrm{~km} \mathrm{~s}^{-1}$ recombination-line velocity of the $\mathrm{H}$ II region.

The millimeter emission can be followed out much farther from the center of the $\mathrm{H}$ II region in the $\mathrm{CO}$ line than in the $\mathrm{CS}$ or millimeter $\mathrm{H}_{2} \mathrm{CO}$ lines. Although the temperature of the $\mathrm{CO}$ line decreases away from the central direction of $\mathrm{G} 49.5-0.4$, the relative strength of the $\mathrm{CO}$ and ${ }^{13} \mathrm{CO}$ lines changes little from the value of 3 measured in the center out to $4^{\prime}$ away, the extent of the ${ }^{13} \mathrm{CO}$ observations. This apparent constancy of the CO opacity $\left(\sim 40\right.$, assuming a terrestial ${ }^{12} \mathrm{C} /{ }^{13} \mathrm{C}$ abundance ratio) and the observation of a $57 \mathrm{~km} \mathrm{~s}^{-1} 6-\mathrm{cm} \mathrm{H}_{2} \mathrm{CO}$ line at a position $\sim 10^{\prime}$ away from the $\mathrm{H}$ II region (see below) once again suggests that, as in W49, the apparent size of the $\mathrm{CO}$ emission region is governed more by changes in the excitation temperature $T_{01}$ than by the optical depth of the $2.6-\mathrm{mm}$ line. 


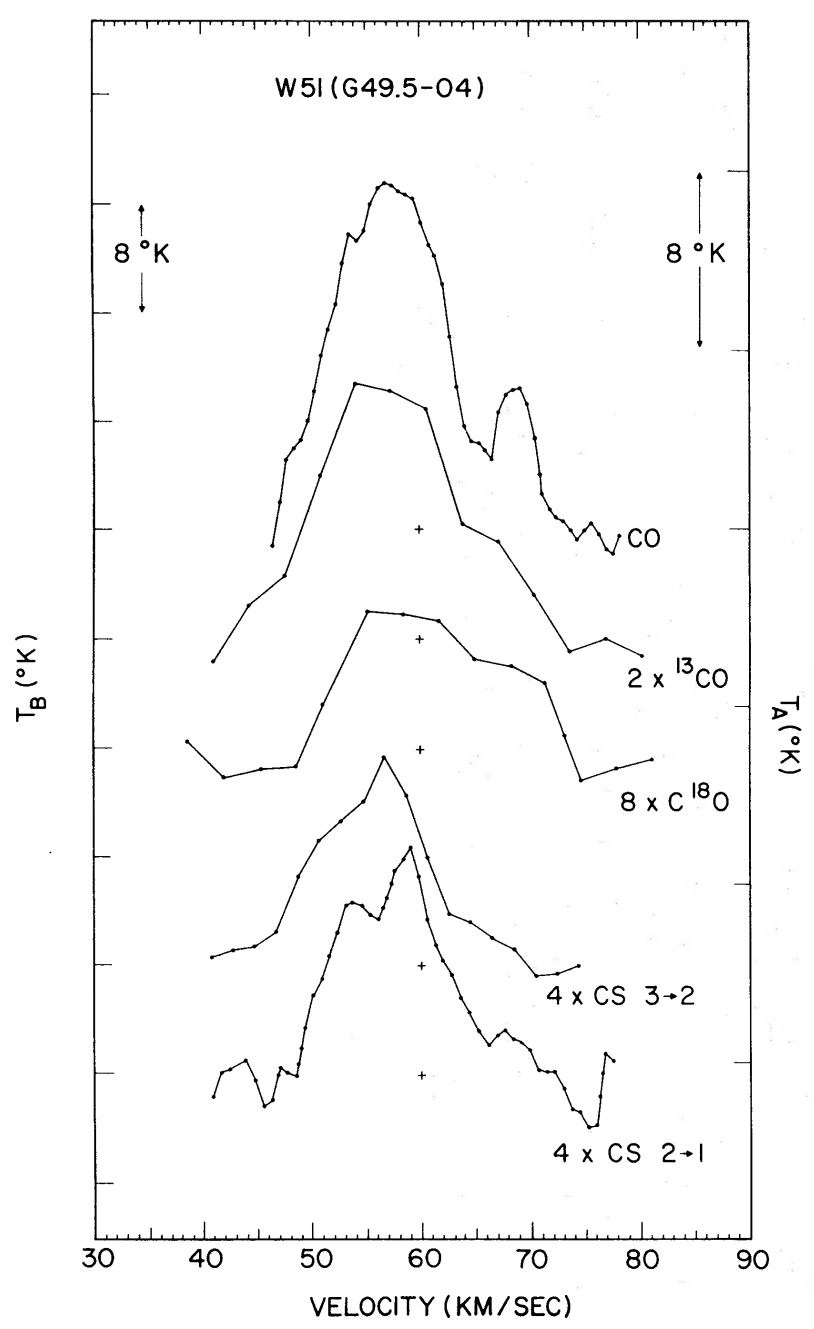

Fig. $9 a$

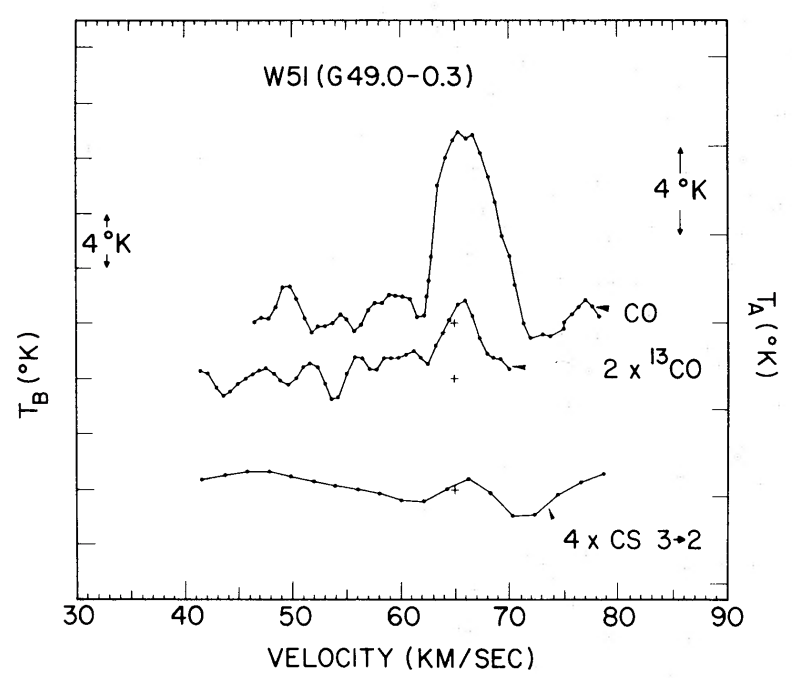

FIG. $9 b$

FIGs. $9 a$ and $9 b$. -Spectra of $\mathrm{CO},{ }^{13} \mathrm{CO}, \mathrm{C}^{18} \mathrm{O}, \mathrm{CS}(J=3 \rightarrow J=2)$, and $\mathrm{CS}(J=2 \rightarrow J=1)$ emissions in W51 at G49.5-0.4 and at G49.0-0.3. The vertical scale on the right is antenna temperature $T_{A}$, and that on the left is $T_{A} / \eta$ ( $\approx$ brightness temperature $T_{B}$, for $\left.T_{B}>10^{\circ} \mathrm{K}\right)$. Note that all spectra other than CO have been expanded vertically. 
In most 6-cm spectra of W51 the $57 \mathrm{~km} \mathrm{~s}^{-1}$ line is severely blended with the much stronger $65 \mathrm{~km} \mathrm{~s}^{-1}$ line, but at about 6' southeast of G49.5-0.4 it is quite distinct. There is no evidence of this line in either $\mathrm{H}_{2} \mathrm{CO}$ or CO near the other W51 H II regions (see figs. $5 b$ and $9 b$ ); therefore, although it is definitely near G49.5-0.4, the angular extent of the cloud is between 2 (CO observations) and $6\left(\mathrm{H}_{2} \mathrm{CO}\right.$ observations) times that of the $\mathrm{H}$ il region.

It is of interest to ask why this $57 \mathrm{~km} \mathrm{~s}^{-1}$ gas appears only faintly in $\mathrm{H}_{2} \mathrm{CO}$ absorption spectra and yet produces the strongest line in the millimeter spectra. From the $\mathrm{CO}$ brightness temperature in figure $9 a$, we estimate that $T_{01}=26^{\circ} \mathrm{K}$, and that the $\mathrm{C}^{18} \mathrm{O}$ and ${ }^{13} \mathrm{CO}$ optical depths are 0.048 and 0.41 . Using terrestrial isotope abundance ratios, the $\mathrm{CO}$ optical depth is between 24 and 36 . The column density of $\mathrm{CO}$ through the center of this cloud is then $\sim 2 \times 10^{19} \mathrm{~cm}^{-2}$. If the $\mathrm{H}_{2} \mathrm{CO} / \mathrm{CO}$ abundance ratio is $\sim 2 \times 10^{-5}$, then the column density $N_{1}$ of $1_{11}$ rotational state $\mathrm{H}_{2} \mathrm{CO}$ molecules should be $\sim 10^{14} \mathrm{~cm}^{-2}$. This corresponds to a $6-\mathrm{cm}$ equivalent width of $6 \mathrm{~km} \mathrm{~s}^{-1}$, and the true optical depth at the peak of the $6-\mathrm{cm}$ line should be $\sim 1$. Although the CO observations indicate that the $57 \mathrm{~km} \mathrm{~s}^{-1}$ cloud has sufficient angular extent to fill the $6^{\prime} \mathrm{H}_{2} \mathrm{CO}$ beam, it is evident from figure $6 a$ that the apparent optical depth at $57 \mathrm{~km} \mathrm{~s}^{-1}$ near G49.5-0.4 is only $\sim 0.05$. A most obvious explanation for this inconsistency is that the $57 \mathrm{~km} \mathrm{~s}^{-1}$ gas is located just behind G49.5-0.4 and is therefore not absorbing the radiation from this source. If this is so, then the $\mathrm{H}_{2} \mathrm{CO}$ will be absorbing only the microwave background plus a small $\left(\leq 1^{\circ} \mathrm{K}\right)$ amount of diffuse galactic radiation. The absorption line temperature should then be $\sim 1^{\circ} \mathrm{K}$-in good agreement with the observed value of $0.8^{\circ} \mathrm{K}$ at $57 \mathrm{~km} \mathrm{~s}^{-1}$ (fig. $5 a$ ).

Mass estimates for the $57 \mathrm{~km} \mathrm{~s}^{-1}$ molecular cloud may be obtained by integrating the $\mathrm{CO}$ column density over the cloud and assuming once again that all the carbon is bound up in CO. The minimum mass of the cloud is then $\simeq 10^{5} M_{\odot}$, an estimate with a large uncertainty due to poor knowledge of the angular extent. This mass is 20 times that of the $\mathrm{H}$ II region $\mathrm{G} 49.5-0.4$ (table 1) and makes this one of the most massive clouds observed outside of the galactic center. The column density estimated from $\mathrm{CO}$ observations $\left(6 \times 10^{22} \mathrm{~cm}^{-2}\right)$ suggests a minimum gas density in the range $3 \times 10^{2}$ to $10^{3} \mathrm{~cm}^{-3}$.

\section{MOLECULAR REGIONS OF HIGH EXCITATION}

In addition to the $\mathrm{CO}$ and $\mathrm{H}_{2} \mathrm{CO}$ lines, we have looked for the $J=2 \rightarrow 1$ and $3 \rightarrow 2$ transitions of CS (at 97.9810 and $146.9692 \mathrm{GHz}$ ) in W49 and W51. ${ }^{4}$ The spontaneous rates of these transitions are $2.1 \times 10^{-5}$ and $6.5 \times 10^{-5} \mathrm{~s}^{-1}$; they therefore pinpoint molecular regions with high excitation rates.

In both W49 and W51 the CS emission is strongly correlated with the positions of the $\mathrm{H}$ II regions. In W49A the $2 \rightarrow 1$ emission is seen at $12 \mathrm{~km} \mathrm{~s}^{-1}$ with a peak antenna temperature of $1.5^{\circ} \mathrm{K}$, and drops to half-intensity less than $2^{\prime}$ away. The $12 \mathrm{~km} \mathrm{~s}^{-1}$ gas is also detected in the $3 \rightarrow 2$ transition with an approximate antenna temperature of $1^{\circ} \mathrm{K}$, but our spectra are very noisy. In W51 the $2 \rightarrow 1$ and $3 \rightarrow 2$ emission comes principally from the $57 \mathrm{~km} \mathrm{~s}^{-1}$ gas (fig. $9 a$ ). The temperatures of both lines are nearly equal and are at half-intensity only $1^{\prime}$ away from G49.5-0.4. In the direction of G49.0-0.3 (fig. $9 b$ ) no CS $3 \rightarrow 2$ emission is seen corresponding to the fairly strong $\mathrm{CO}$ line at $66 \mathrm{~km} \mathrm{~s}^{-1}$.

CS opacity estimates from isotope line strengths are difficult on account of the low CS intensities. The $\mathrm{C}^{34} \mathrm{~S} 3 \rightarrow 2$ transition at $57 \mathrm{~km} \mathrm{~s}^{-1}$ has been detected at onequarter the intensity of the CS line. If the terrestrial isotope ratio, ${ }^{32} \mathrm{~S} /{ }^{34} \mathrm{~S}$, of 25 holds for W51, then the $3 \rightarrow 2$ CS line is probably optically thick, and its brightness tem-

\footnotetext{
${ }^{4}$ An extensive survey and discussion of the CS lines will appear in Solomon et al. (1972a).
} 
perature gives a good measure of the excitation temperature $\left(\sim 7.4^{\circ} \mathrm{K}\right.$ [eq. (5a)]). If the $2 \rightarrow 1$ transition is also optically thick, its excitation temperature is $7.3^{\circ} \mathrm{K}$. Similar low excitation temperature may exist in the HCN (Snyder and Buhl 1971) and 2-mm $\mathrm{H}_{2} \mathrm{CO}$ (Thaddeus et al. 1971) transitions which also require high excitation rates in order to be excited above $2.7^{\circ} \mathrm{K}$. In contrast, the $\mathrm{CO}$ excitation temperature, probably a lower limit to the gas kinetic temperature, is $\sim 26^{\circ} \mathrm{K}$ near the W51 peak.

Though they are excited well above the cosmic background near the $\mathrm{H}$ II regions, it is clear that the CS $3 \rightarrow 2$ and $2 \rightarrow 1$ transitions are not thermalized in any of the observed clouds. Moreover, the level of excitation appears to decrease away from the $\mathrm{H}$ II regions. Excitation by electrons in gas bordering the $\mathrm{H}$ il regions would explain the correlation between the high-excitation gas and $\mathrm{H}$ II regions; however, the mechanism maintaining a high electron density unfortunately would probably dissociate the molecules. Also because both the $A$ 's and the electron collision rates scale with the transition matrix element, electrons should excite CO and CS almost equally. At a kinetic temperature of $50^{\circ} \mathrm{K}$, the observed $\mathrm{CO}$ excitation requires an electron density of $\sim 10^{2} \mathrm{~cm}^{-3}, 30$ times greater than that needed for the CS.

If instead the observed brightness of the CS lines is provided solely by collisions with neutral particles (neglecting the photon scattering), then the gas density must be $\sim 6 \times 10^{5}$ and these densities must exist over a region comparable in area to the $\mathrm{H}$ II regions $\left(\sim 9 \operatorname{arcmin}^{2}\right)$. It has been argued (Goldsmith 1972) that high excitation temperatures and even inversions can be produced by neutral particle collisions under conditions when multiquanta $(\Delta J>1)$ collisions have a strength equal to those of $\Delta J=1$. However, this is true only in the limit of $\tau \ll 1$ since absorption of trapped photons depopulates excited states if $\tau \geq 1$. For CS the evidence from the isotopic lines as well as the relative strength of the 3-2 and 2-1 transitions (see Solomon et al. $1972 a$ ) indicates $\tau \gg 1$. Therefore, the excitation-temperature calculations of Goldsmith (1972) do not apply and the necessary neutral density estimated above must be regarded as approximately correct for the pure collision-dominated case. Such a high neutral particle density, unless only in a thin shell around the $\mathrm{H}$ II region or in small condensed objects, seems unlikely in view of the much lower average densities in the $\mathrm{H}$ II regions derived from radio continuum measurements and in view of the short dynamical timescales expected for such a dense and dusty gas.

The problems confronting models for the CS excitation which involve only collisions over a large volume suggest that the effects of radiative transfer should be considered more seriously. The near equality of the brightness temperatures in the two CS lines at different frequencies is suggestive of an optically thick medium at a temperature much greater than $h v / \kappa$. Thus the observed CS line radiation could be scattered radiation from compact, high-temperature objects which are much smaller than the apparent size of the CS emission region. The compact sources could be dense regions in which the CS is thermalized at a high temperature. High pressures in or on the border of the $\mathrm{H}$ II regions would be conducive to the compression of the neutral gas to a high density and thus explain the general correlation of the CS intensities with the $\mathrm{H}$ II regions. These high-density molecular regions may be protostars or protoclusters which will become compact $\mathrm{H}$ II regions after the formation of massive stars. Very dense $\left(n_{e}>10^{4} \mathrm{~cm}^{-3}\right)$ knots of ionized gas observed in both W49 and W51 (§ I) may represent a later evolutionary phase of dense molecular regions.

Therefore, although the observed excitation in the transitions of CS (and similar molecules) well above the cosmic background implies a very high neutral gas density $\left(\geq 10^{5} \mathrm{~cm}^{-3}\right)$ somewhere in the cloud, we feel that such is probably not required over the full angular extent of the CS emission region. It would then be erroneous to conclude that this high density was typical of the whole cloud and to derive a mass estimate from it. 


\section{CONCLUSIONS}

1. Five of the seven observed clouds ( 3 and $14 \mathrm{~km} \mathrm{~s}^{-1}$ in W49A, and 50,57 , and $65 \mathrm{~km} \mathrm{~s}^{-1}$ in W51) are associated with one or more of the $\mathrm{H}$ II regions and show moderately broad lines $\left(4 \mathrm{~km} \mathrm{~s}^{-1} \leqslant \Delta V \leqslant 15 \mathrm{~km} \mathrm{~s}^{-1}\right)$. The $65 \mathrm{~km} \mathrm{~s}^{-1}$ cloud in W51 extends over a region containing at least three $\mathrm{H}$ II regions, and appears as a selfabsorption feature in the $\mathrm{CO}$ spectrum of G49.5-0.4. The two other clouds ( 39 and $62 \mathrm{~km} \mathrm{~s}^{-1}$ in W49A) show narrow $\mathrm{H}_{2} \mathrm{CO}$ lines and are probably dark nebulae unrelated to any $\mathrm{H}$ il regions.

2. For three of the five clouds we have estimated the masses and find them to be in the range $10^{4}-10^{5} M_{\odot}$. These masses, almost certainly minimum values, are more than 10 times those of the associated $\mathrm{H}$ II regions and only a little less than the masses of some molecular clouds in the galactic center.

3. The 3 and $14 \mathrm{~km} \mathrm{~s}^{-1}$ clouds in W49A appear to be approaching this $\mathrm{H}$ in region at velocities of $\sim 5 \mathrm{~km} \mathrm{~s}^{-1}$. The $\mathrm{CO}$ observations suggest that the gas kinetic temperature in the $14 \mathrm{~km} \mathrm{~s}^{-1}$ cloud is highest near the $\mathrm{H}$ II region.

4. The 6- $\mathrm{cm} \mathrm{H}_{2} \mathrm{CO}$ observations of three molecular clouds which also have intense millimeter emission lines ( 3 and $14 \mathrm{~km} \mathrm{~s}^{-1}$ in W49A, and $57 \mathrm{~km} \mathrm{~s}^{-1}$ in W51) indicate that these clouds are considerably more extensive than either the associated $\mathrm{H}$ II regions or the half-intensity sizes determined from the millimeter-line observations. Some of the millimeter emission lines, especially those of CS, show a strong correlation of their intensities with the positions of $\mathrm{H}$ II regions.

5. Determination of the excitation temperature in the $\mathrm{H}_{2} \mathrm{CO} 6-\mathrm{cm}$ transition from the two narrow lines in the direction of W49 yields $T_{12}=1.76^{\circ} \pm 1.2^{\circ} \mathrm{K}$.

We thank R. Taam for assistance with the $\mathrm{H}_{2} \mathrm{CO}$ observations and L. B. Lucy for comments on an earlier version of this paper.

\section{REFERENCES}

Allen, C. W. 1963, Astrophysical Quantities (2d ed.; London: Athlone Press).

Buhl, D., Snyder, L. E., Schwartz, P. R., and Barrett, A. H. 1969, Ap. J. (Letters), $158, \mathrm{L97.}$

Goldsmith, P. F. 1972, Ap. J., 176, 597.

Gordon, M. A., and Wallace, D. C. 1971, Ap. J., 167, 235.

Goss, W. M., and Shaver, P. A. 1970, Australian J. Phys., Ap. Suppl., 14, 1.

Heiles, C. 1972, NRAO Symposium on Interstellar Molecules, October 1971, ed. M. A. Gordon (New York: John Wiley \& Sons) (in press).

Jefferts, K. B., Penzias, A. A., and Wilson, R. W. 1970, Ap. J. (Letters), 161, L87.

Kutner, M., Scoville, N. Z., Solomon, P. M., and Thaddeus, P. 1973 (in preparation).

Mezger, P. G., and Henderson, A. P. 1967, Ap. J., 147, 471.

Mezger, P. G., Schraml, J., and Terzian, Y. 1967, Ap. J., 150, 807.

Miley, G. K., Turner, B. E., Balick, B., and Heiles, C. 1970, Ap. J. (Letters), 160, L119.

Palmer, P., Zuckerman, B., Buhl, D., and Snyder, L. E. 1969, Ap. J. (Letters), 156, L147.

Penzias, A. A., Jefferts, K. B., Liszt, H., Wilson, R. W., and Solomon, P. M. $1972 a$ (in preparation).

Penzias, A. A., Jefferts, K. B., and Wilson, R. W. 1971 , Ap. J., 165, 229.

Penzias, A. A., Solomon, P. M., Jefferts, K. B., and Wilson, R. W. 1972b, Ap. J. (Letters), 174, L43.

Penzias, A. A., Solomon, P. M., Wilson, R. W., and Jefferts, K. B. 1971b, Ap. J. (Letters), 168, L53.

Raimond, E., and Eliasson, B. 1969, Ap. J., 155, 817.

Reifenstein, E. C., Wilson, T. L., Burke, B. F., Mezger, P. G., and Altenhoff, W. J. 1970, Astr. and $A p ., 4,357$.

Rogers, A. E., Moran, J. M., Crowther, P. P., Burke, B. F., Meeks, M. L., Ball, J. A., and Hyde, G. M. 1966, Phys. Rev. Letters, 17, 450.

Schraml, J., and Mezger, P. G. 1969, Ap. J., 156, 269.

Scoville, N. Z., Solomon, P. M., and Thaddeus, P. 1972, Ap. J., 172, 335.

Shaver, P. A. 1969, M.N.R.A.S., 142, 273.

Snyder, L. E., and Buhl, D. 1971, Ap. J. (Letters), 163, L47.

Solomon, P. M., Jefferts, K. B., Penzias, A. A., Wilson, R. W., and Liszt, H. 1972a (in preparation). 
Solomon, P. M., Scoville, N. Z., Jefferts, K. B., Penzias, A. A., and Wilson, R. W. 1972b, Ap. J. (in press).

Solomon, P. M., and Werner, M. W. 1971, Ap. J., 165, 41.

Thaddeus, P., Wilson, R. W., Kutner, M., Penzias, A. A., and Jefferts, K. B. 1971, Ap. J. (Letters), 168, L59.

Tucker, K. D., Tomasevich, B. R., and Thaddeus, P. 1971, Ap. J. (Letters), 161, L153.

Weaver, H., Dieter, N. H., and Williams, D. R. W. 1969, Ap. J. Suppl., 16, 219.

Westerhout, G. 1958, B.A.N., 14, 215.

Whiteoak, J. B., and Gardner, F. F. 1970, Ap. Letters, 5, 5.

Wilson, T. L., Mezger, P. G., Gardner, F. F., and Milne, D. K., 1970, Ap. Letters, 5, 99.

Wynn-Williams, C. G. 1969, M.N.R.A.S., 142, 453.

Zuckerman, B., Buhl, D., Palmer, P., and Snyder, L. E. 1970, Ap. J., 160, 485. 
